Article

\title{
New Insights into the Microstructural Changes During the Processing of Dual-Phase Steels from Multiresolution Spherical Indentation Stress-Strain Protocols
}

\author{
Ali Khosravani ${ }^{1}$, Charles M. Caliendo ${ }^{2}$ and Surya R. Kalidindi ${ }^{1,2, * * 1}$ \\ 1 The George W. Woodruff School of Mechanical Engineering, Georgia Institute of Technology, Atlanta, \\ GA 30332, USA; alikhosravani@gatech.edu \\ 2 School of Materials Science and Engineering, Georgia Institute of Technology, Atlanta, GA 30332, USA; \\ ccaliendo@gatech.edu \\ * Correspondence: surya.kalidindi@me.gatech.edu; Tel.: +1-404-385-2886
}

Received: 1 December 2019; Accepted: 19 December 2019; Published: 21 December 2019

\begin{abstract}
In this study, recently established multiresolution spherical indentation stress-strain protocols have been employed to derive new insights into the microstructural changes that occur during the processing of dual-phase (DP) steels. This is accomplished by utilizing indenter tips of different radii such that the mechanical responses can be evaluated both at the macroscale (reflecting the bulk properties of the sample) and at the microscale (reflecting the properties of the constituent phases). More specifically, nine different thermo-mechanical processing conditions involving different combinations of intercritical annealing temperatures and bake hardening after different amounts of cold work were studied. In addition to demonstrating the tremendous benefits of the indentation protocols for evaluating the variations within each sample and between the samples at different material length scales in a high throughput manner, the measurements provided several new insights into the microstructural changes occurring in the alloys during their processing. In particular, the indentation measurements indicated that the strength of the martensite phase reduces by about $37 \%$ when quenched from $810^{\circ} \mathrm{C}$ compared to being quenched from $750{ }^{\circ} \mathrm{C}$, while the strength of the ferrite phase remains about the same. In addition, during the $10 \%$ thickness reduction and bake hardening steps, the strength of the martensite phase shows a small decrease due to tempering, while the strength of the ferrite increases by about $50 \%$ by static aging.
\end{abstract}

Keywords: dual-phase steels; spherical indentation; multi length-scale mechanical testing

\section{Introduction}

Dual-phase (DP) steels with a combination of high tensile strength, high work-hardening rate, and good ductility are being evaluated for the lightweighting of critical structural components in automobiles [1-5]. The desired combinations of properties are achieved in DP steels through the use of multiple thermo-mechanical processing steps. These processing steps typically include intercritical annealing at $730-830{ }^{\circ} \mathrm{C}$ for a few minutes up to an hour, quenching at different cooling rates, cold working to different deformation levels, and aging at $100-250{ }^{\circ} \mathrm{C}$ up to few hours. The last two steps are typically referred to as bake hardening [6-23]. During the intercritical annealing treatment, the material is heated up to a temperature where the austenite and the ferrite phases are stable. During the subsequent quenching to the room temperature, the austenite transforms to the much harder martensite phase [17,23-29], which essentially controls the properties of the DP steel. It is evident from the $\mathrm{Fe}-\mathrm{C}$ phase diagram (see Figure 1) that the different intercritical annealing temperatures 
will result in different volume fractions of the martensite phase [24]. Furthermore, the amount of carbon content in the martensite (as a solid solution) varies significantly with the chosen intercritical annealing temperature (for example, it can change from 0.17 to $0.77 \mathrm{wt} \%$ when the intercritical annealing temperature is reduced from 830 and $730^{\circ} \mathrm{C}$ ), while the corresponding change in the ferrite phase is insignificant (only about 0.01-0.02 wt.\%). Furthermore, the relevant section of the phase diagram (see Figure 1) suggests that intercritical annealing at lower temperatures results in a smaller volume fraction of martensite but with a higher carbon content. As already mentioned, another important component in the processing of DP steels is the bake hardening $(\mathrm{BH})[6-23]$ step, which includes cold working followed by aging heat treatment. This step is known to impart DP steels with a characteristic property known as continuous yielding, which is generally attributed to the production and pinning of dislocations in the ferrite component, especially in the vicinity of ferrite/martensite interfaces $[1,7-14,16,18,19,22,28,30-34]$.
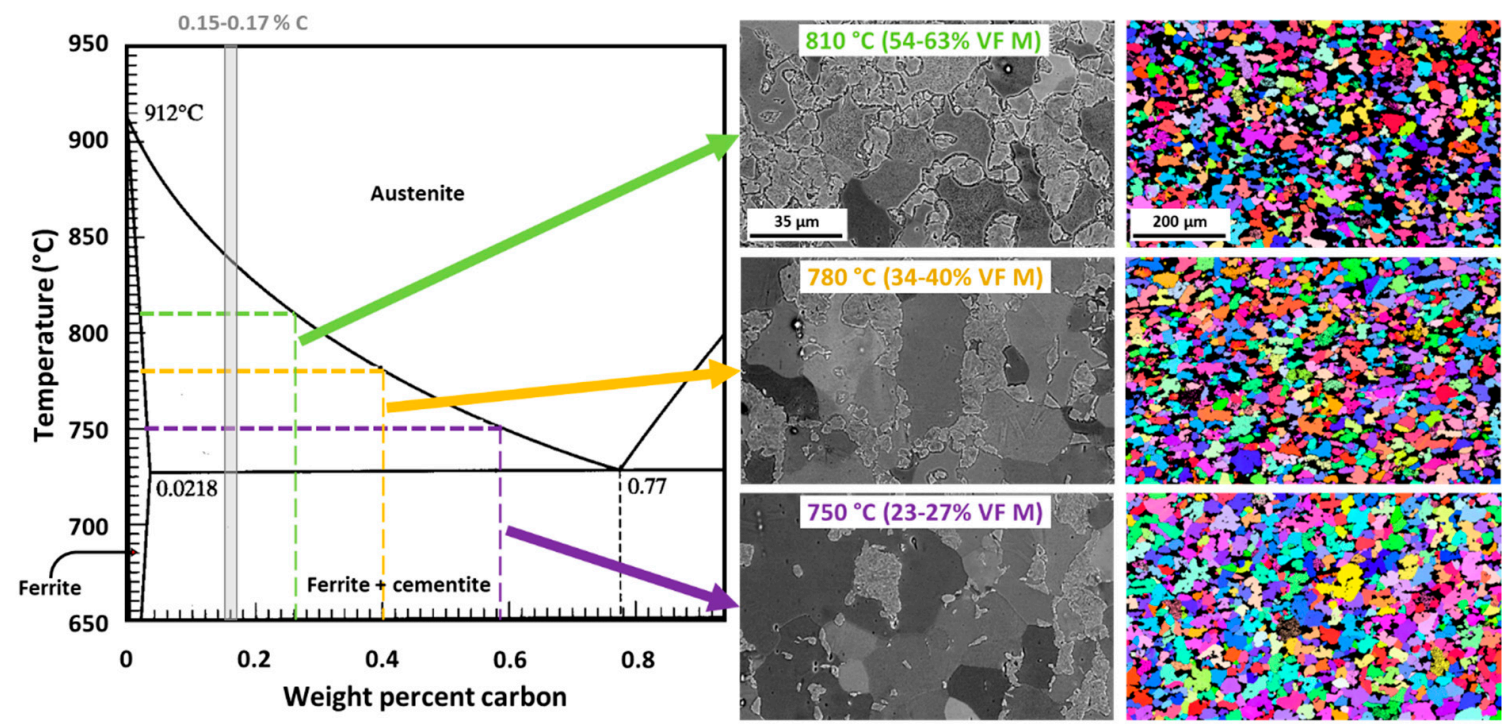

Figure 1. Small section of the binary Fe-C phase diagram showing the different compositions and microstructures produced from three different intercritical annealing treatments on the initial low carbon steel with $0.15-0.17 \mathrm{wt}$ \% carbon content. The intercritical annealing temperatures selected for this study were $750{ }^{\circ} \mathrm{C}, 780^{\circ} \mathrm{C}$, and $810^{\circ} \mathrm{C}$. The microstructures are shown as back-scattered electrons (BSE) and electron-backscattered diffraction (EBSD) maps.

The discussion above points out the difficulties encountered in the optimization of the processing of DP steels to meet the desired combination of properties [1,35,36]. This is mainly because of the need to explore a very large and complex process space (each element of this space should specify the entire process history, including the complete sequence of substeps described earlier). One of the central bottlenecks comes from the lack of reliable information on the changes in the properties of the constituent phases (i.e., martensite and ferrite) as a function of the process parameters. A number of prior studies [37-52] have employed indentation techniques for this task. However, most of these studies have employed sharp indenters and reported large variances in the measured values. A summary of such measurements in DP steels is presented in Table 1, which shows a range of 2-7 GPa for the hardness of the ferrite phase and a range of 3-13 GPa for the hardness of the martensite phase. The large variations in the reported hardness data have hindered attempts aimed at extracting quantitative physical insights that could guide the rational design of DP process histories to achieve desirable combinations of bulk properties. In recent work [53-61], it has been demonstrated that indentation yield strength is a much more reproducible and reliable measure of the intrinsic plastic strength of the microscale constituents in a heterogeneous material, and could be estimated from the recently established spherical indentation stress-strain protocols [62,63]. Using this analysis method, it has been shown [57] that the indentation 
yield strength is very sensitive to the carbon content in the lath martensite; increasing C content from 0.13 to $0.30 \mathrm{wt}$. $\%$ improves the indentation yield strength by $42-48 \%$ and the indentation work hardening by $27-47 \%$. In this work, we extend and employ these techniques to provide quantitative insights into the changes in the yield strengths of the martensite and ferrite phases in DP steels, especially during the intercritical annealing and the bake hardening steps.

Table 1. Summary of hardness measurements in martensite and ferrite from prior literature.

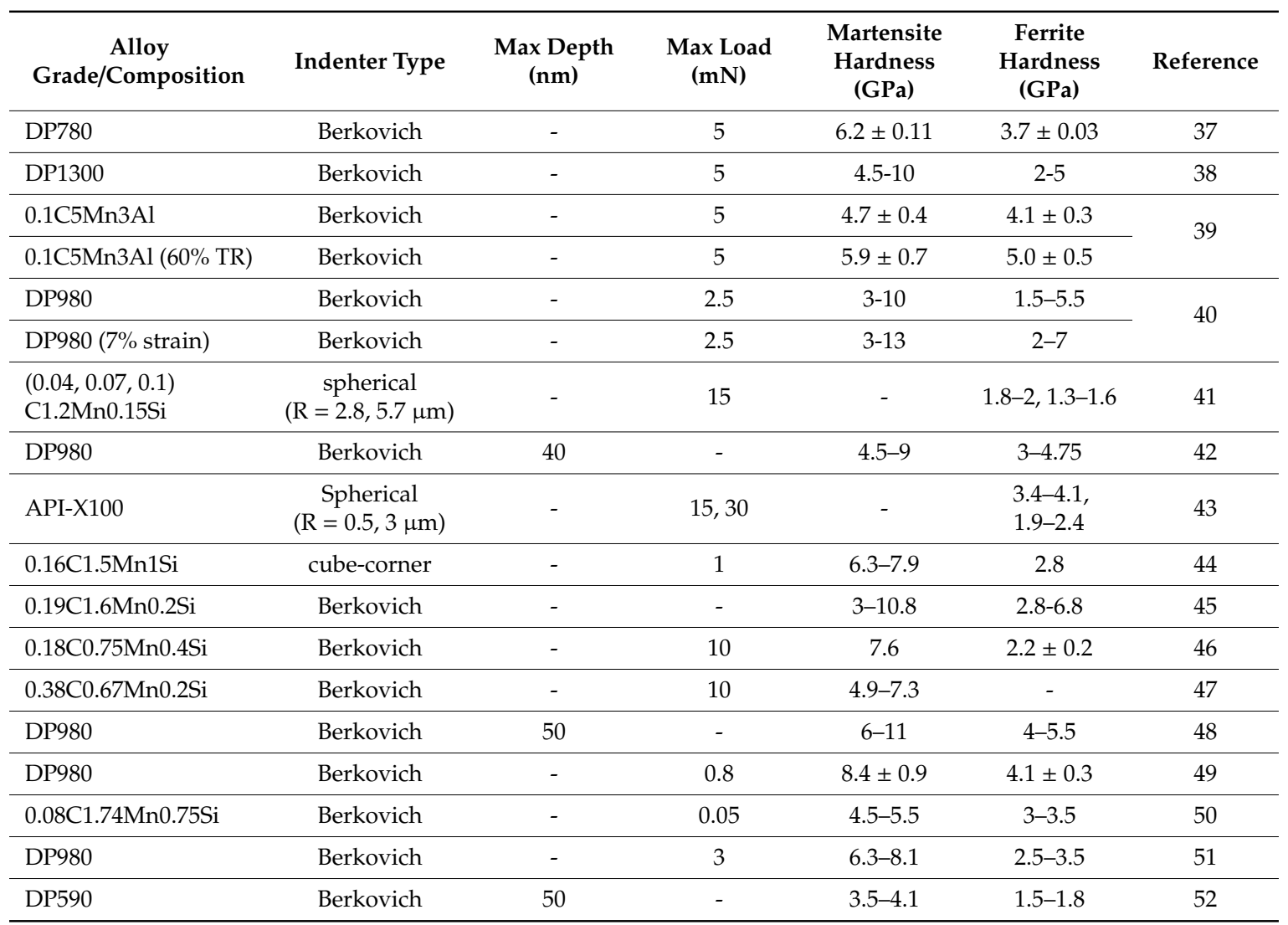

\section{Materials and Method}

\subsection{Sample Preparation}

A four mm thick strip of low carbon steel with a chemical composition (in wt.\%) of 0.16C, 1.4Mn, 0.04P, and 0.04S was used to produce the DP steel samples needed for this study. Small coupons of the low carbon steel with dimensions of $10 \mathrm{~mm} \times 20 \mathrm{~mm} \times 4 \mathrm{~mm}$ were cut, and heat-treated at $450{ }^{\circ} \mathrm{C}$ for $2 \mathrm{~h}$ to obtain a starting annealed microstructure. Three intercritical annealing temperatures of $750{ }^{\circ} \mathrm{C}, 780{ }^{\circ} \mathrm{C}$, and $810^{\circ} \mathrm{C}$ were selected to produce different volume fractions of the martensite phase after quenching. The heat treatment was carried out in a molten salt bath, LIQUID HEAT 168 from Houghton International (Houghton International Inc., Norristown, PA, USA), to ensure quick heating and uniform temperature inside the small coupons. After holding three samples for $4 \mathrm{~min}$ at each selected intercritical annealing temperature, they were quenched in an oil bath to room temperature. Of each set of three samples thus produced, one sample was retained without bake hardening. The other two samples from each set were subjected to thickness reductions of $5 \%$ and $10 \%$ by cold rolling, respectively, and heat-treated at $170{ }^{\circ} \mathrm{C}$ for $20 \mathrm{~min}$ and quenched in water. As a result of the protocols described above, a total of nine samples with nine different processing conditions were produced. The sample labeling was designed to reflect the processing history in the form "intercritical annealing temperature-thickness reduction percentage-bake hardening temperature". As an example, sample 810-10-170 indicates quenching after an intercritical annealing temperature of $810{ }^{\circ} \mathrm{C}$ followed 
by $10 \%$ thickness reduction and bake hardening at $170{ }^{\circ} \mathrm{C}$ for $20 \mathrm{~min}$. Likewise, sample $810-00-000$ indicates that the sample was subjected to only intercritical annealing at $810^{\circ} \mathrm{C}$ followed by quenching.

Samples were prepared for microscopy and indentation using standard metallography procedures. This included grinding with silicon carbide papers down to a grade of 4000 and polishing sequentially with suspensions of $3 \mu \mathrm{m}$ and $1 \mu \mathrm{m}$ diamond particles. The final step of polishing included vibro-polishing (Struers Inc., Cleveland, OH, USA) for $24 \mathrm{~h}$ using colloidal silica suspension. After polishing, SEM (scanning electron microscopy) images and EBSD (electron backscatter diffraction) (EDAX Inc., Mahwah, NJ, USA) maps were obtained from all samples using a TESCAN MIRA3 (TESCAN USA Inc., Warrendale, PA, USA) scanning electron microscope with a field emission gun set at $20 \mathrm{kV}$. High contrast in electron channeling contrast image (ECCI) at sub-micron resolution was achieved with a working distance of 5-6 $\mathrm{mm}$ and a voltage of $30 \mathrm{kV}$.

\subsection{Spherical Nano-Indentation Stress-Strain Protocols}

After imaging, spherical nanoindentation tests were carried out in an Agilent G200 Nanoindenter (KLA Inc., Milpitas, CA, USA). As these measurements were aimed at obtaining responses from the ferrite and martensite regions in the sample, smaller indenter tips of radii $1 \mu \mathrm{m}$ and $16 \mu \mathrm{m}$ were employed in these tests. At least 20-30 indentation measurements were conducted for each phase (i.e., ferrite and martensite) on each sample. A constant strain rate of $0.05 \mathrm{~s}^{-1}$ was used with a maximum depth of $200 \mathrm{~nm}$ and $350 \mathrm{~nm}$ for the indenter tips with radii of $1 \mu \mathrm{m}$ and $16 \mu \mathrm{m}$, respectively. The Agilent G200 Nanoindenter used in this study had an XP head and CSM (continuous stiffness measurement) module. The CSM superimposes small sinusoidal load/unload cycles on the monotonic loading history with a frequency of $45 \mathrm{~Hz}$ and an amplitude of $2 \mathrm{~nm}$. The CSM capability allows an accurate estimation of contact radius used in calculating indentation stress and indentation strain [62,63]. The analysis protocols used in the nanoindentation tests are briefly presented next.

Let $P, h_{e}, E_{e f f}$, and $R_{e f f}$ denote the indentation load, the elastic indentation depth, the effective modulus of the indenter-sample system, and the effective radius of the indenter-sample system, respectively (see Figure 2). These variables can be related to each other using Hertz's theory [64] for elastic contact between two isotropic bodies as

$$
\begin{gathered}
P=\frac{4}{3} E_{e f f} \sqrt{R_{e f f} h_{e}^{3}}, \\
\frac{1}{E_{e f f}}=\frac{1-v_{i}^{2}}{E_{i}}+\frac{1-v_{s}^{2}}{E_{s}}, \\
\frac{1}{R_{e f f}}=\frac{1}{R_{i}}+\frac{1}{R_{s}},
\end{gathered}
$$

where $E_{i}, v_{i}$ and $E_{s}, v_{s}$ are Young's modulus and Poisson ratio for the indenter and the sample, respectively. For the initial elastic loading when the surface of the sample is still flat, the effective radius, $R_{e f f}$, is equal to the indenter radius, $R_{i}$. Therefore, it would be possible to extract $E_{e f f}$ from the measured load-displacement using standard regression techniques. One of the central challenges in this analysis comes from the need for a highly accurate estimation of the effective point of the initial contact (i.e., zero-point correction) [62,63,65-71]. This zero-point correction helps in dealing with many of the unavoidable issues encountered at initial contact, including imperfections in indenter shape and non-ideal surface conditions (e.g., oxide layer, surface roughness). In the protocols used in this work, the initial contact point was determined by finding load and displacement corrections $\left(P^{*}\right.$ and $\left.h^{*}\right)$ from the following relation derived from Equation (1) [62]:

In Equation (4), $S$ is the measured elastic unloading stiffness obtained using the CSM capability mentioned earlier, and $\widetilde{P}$ and $\widetilde{h}$ are the raw measurements of load and displacement, respectively. To estimate $P^{*}$ and $h^{*}$, Equation (4) is re-cast as 


$$
S=\frac{3 P}{2 h_{e}}=\frac{3}{2} \frac{\left(\widetilde{P}-P^{*}\right)}{\left(\widetilde{h}-h^{*}\right)} .
$$

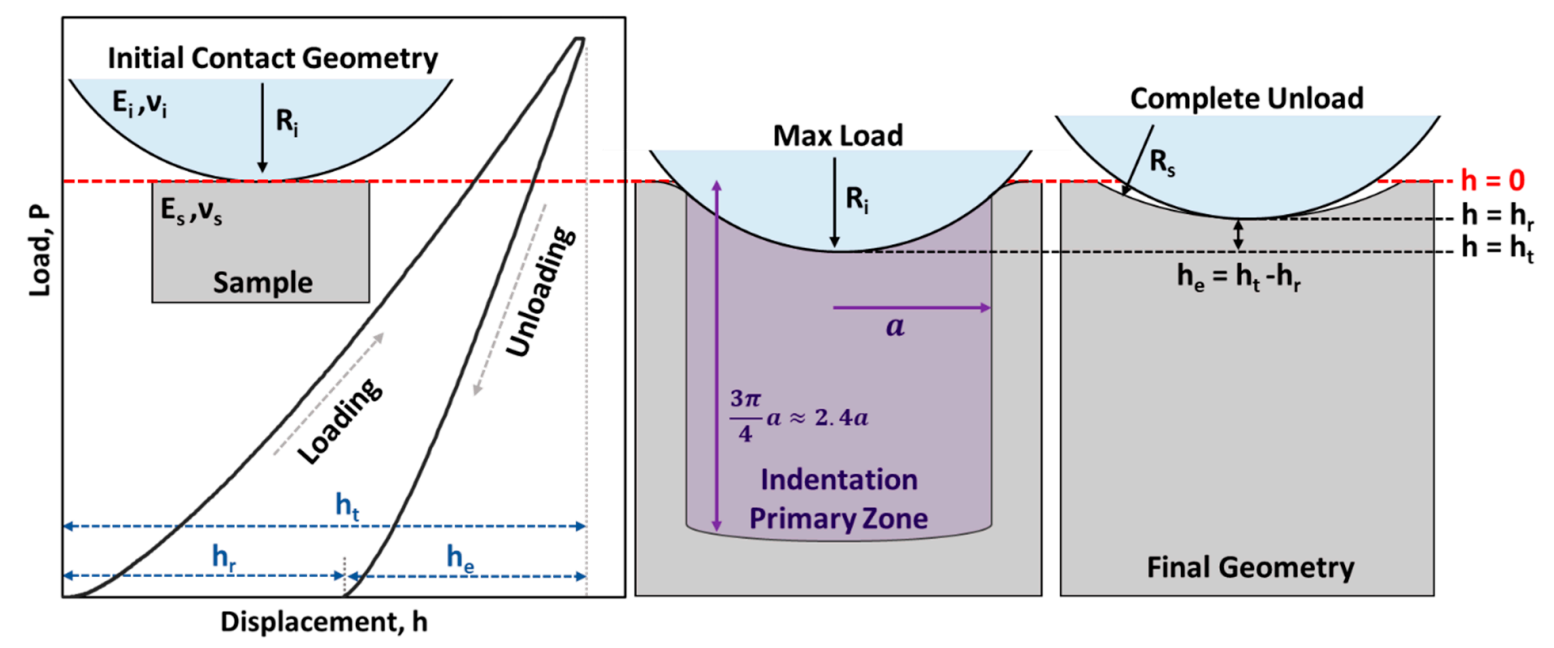

Figure 2. Schematic of a typical measured spherical indentation load-displacement curve and their corresponding initial and final contact geometries. The indentation primary zone within which the majority of deformation occurs is highlighted as a purple cylinder with a radius and height of $a$ and $2.4 a$, respectively.

The form of Equation (5) allows an accurate estimation of the zero-point corrections (i.e., values of $P^{*}$ and $h^{*}$ ) by performing linear regression between the measured values of $\widetilde{P}-\frac{2}{3} S \widetilde{h}_{e}$ and $S$;

$$
\widetilde{P}-\frac{2}{3} \widetilde{S h}_{e}=-\frac{2}{3} h^{*} S+P^{*} .
$$

Figure 3a-c illustrates the main steps involved in the analyses of the nanoindentation measurement reports in this study. An example measured raw load-displacement data as shown in Figure 3a. The application of the zero-point correction described in Equation (5) is illustrated in Figure $3 b$, where the expected linear portion based on Hertz's theory is shown in yellow (the corresponding segment in the load-displacement curve is shown in the inset in Figure 3a). After the zero-point correction, $E_{e f f}$ can be estimated by performing a linear regression between $P$ and $h^{3 / 2}$ in the initial elastic portion of the measured load-displacement curve (highlighted in yellow in Figure 3a) [62]. The estimated value of $E_{e f f}$ is then used to estimate the continuously evolving contact radius, $a$, using the following relationship derived from Hertz's theory [64]:

$$
a=\frac{S}{2 E_{\text {eff }}} .
$$

An important aspect of Equation (6) is that it is applicable at any point in the complex elastic-plastic loading-unloading cycles applied to the sample. By Equation (6), the effective indentation modulus measured from the initial elastic loading segment is assumed to remain constant throughout the elastic-plastic loading applied to the sample. Estimation of the continuously evolving contact radius allows the estimation of indentation stress and indentation strain [62] defined as follows:

$$
\begin{aligned}
\sigma_{\text {ind }} & =\frac{P}{\pi a^{2}}, \\
\varepsilon_{\text {ind }} & =\frac{4}{3 \pi} \frac{h_{t}}{a} .
\end{aligned}
$$


An example indentation stress-strain curve extracted using the above protocols presented in Figure 3c. The spherical nanoindentation stress-strain protocols described above have been validated extensively in both experiments [53-61,72-95] and numerical simulations (performed using finite element models) [96-99]. As a result of these prior validations, we are now fairly confident in obtaining highly reproducible indentation stress-strain curves on a broad variety of material samples.
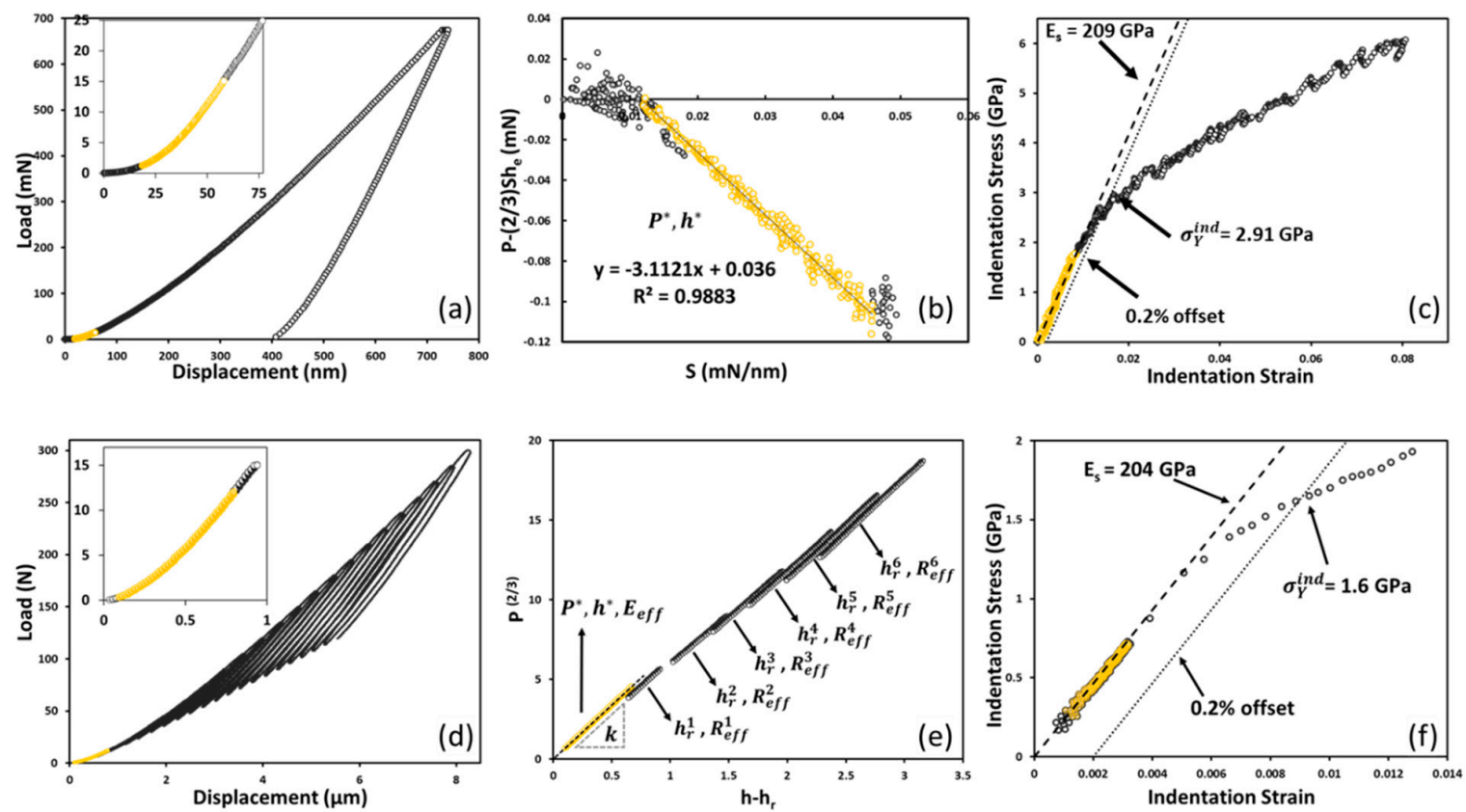

Figure 3. (a) Typical load-displacement curve from the nanoindentation test and the initial elastic segment (highlighted in yellow) identified in (b). (b) The identification of the effective zero-point by linear regression analyses of the linear portion of the curve between $\mathrm{P}-\frac{2}{3} S h_{e}$ and $S$. This linear regression allows the estimation of the zero-point corrections, $P^{*}$ and $h^{*}$. (c) Indentation stress-strain curve extracted from the corrected nanoindentation data. (d) Typical load-displacement curve from the microindentation test in absence of CSM (continuous stiffness measurement) measurements, using a multitude of unloading segments. The initial elastic segment is highlighted in yellow. (e) The identification of the effective zero-point by linear regression analyses of the straight line between $P^{2 / 3}$ and $h-h_{r}$. This analysis allows the estimation of $P^{*}$ and $h^{*}$. (f) Indentation stress-strain curve extracted from the corrected data for the microindentation test.

\subsection{Spherical Micro-Indentation Stress-Strain Protocols}

As already noted earlier, our interest here also includes bulk plastic properties of the various samples produced for the study. The bulk mechanical response of each sample was measured using a customized Zwick-Roell Z2.5 hardness (microindentation) tester (ZwickRoell Group, Ulm, Germany). For these tests, a spherical indenter with a $6350 \mu \mathrm{m}$ radius indenter tip was used. The indenter is made of tungsten carbide to ensure high rigidity of the indenter. A total of 10-15 tests were conducted at randomly selected locations on each sample. A constant crosshead speed of $0.1 \mathrm{~mm} / \mathrm{min}$ was used in all microindentation tests reported in this study.

As the Zwick-Roell Z2.5 tester does not have CSM capability, one needs a different strategy to extract indentation stress-strain curves from the spherical microindentation measurements. In recent work, it was shown that one can estimate the contact radius reliably from superimposed unloading segments (corresponding to about 30-50\% of the peak force) when the CSM option is not available [63]. Figure 3d shows an example measurement of the load-displacement data in multiple loading-unloading cycles in the spherical microindentation protocols employed in this work. In these protocols, each unloading segment is assumed to be purely elastic and is analyzed using Hertz's theory [64]: 


$$
\begin{gathered}
\left(\widetilde{h}_{e}-h^{*}\right)=k\left(\widetilde{P}-P^{*}\right)^{\frac{2}{3}}, \\
k=\left[\frac{3}{4} \frac{1}{E_{e f f}} \frac{1}{\sqrt{R_{e f f}}}\right],
\end{gathered}
$$

where $P^{*}$ and $h^{*}$ represent once again the zero-point corrections. To estimate the zero-point load and displacement corrections, $P^{*}$ and $h^{*}$, a least-squares regression was applied to the initial measured load-displacement data in the elastic regime in Equation (9). As the indentation starts on a flat surface, $R_{e f f}$ in the initial elastic regime (highlighted in yellow in Figure 3d) is equal to the indenter radius, $R_{i}$. Thus, one can estimate $E_{\text {eff }}$ from Equation (10), which is assumed to remain constant even after the specimen has undergone plastic deformation.

Plastic deformation under the indenter leads to a continuous evolution of $R_{e f f}$. Each subsequent unloading (after the estimation of $E_{e f f}$ from the initial elastic loading segment) is analyzed using Hertz's theory, but this time with a focus on estimating the evolving values of $R_{\text {eff }}$ and the values of the indentation contact radius, $a$. This is accomplished by regressing each unloading curve in Figure $3 \mathrm{~d}$ to Hertz's theory expressed as

$$
h-h_{r}=k(P)^{\frac{2}{3}},
$$

where $h_{r}$ denotes residual displacement (after complete unloading; see Figure 2). This regression analysis allows the determination of the values of $h_{r}$ and $R_{e f f}$ (see Equation (10)) corresponding to each unloading segment obtained in the test. Figure $3 \mathrm{e}$ illustrates the above protocol for six selected unloading segments (out of a much larger number of unloading segments depicted in Figure 3d). The values of the contact radius $a$ are then estimated using Hertz's theory as

$$
a=\sqrt{R_{e f f}\left(h_{s, \max }-h_{r}\right)},
$$

where $h_{s, \max }$ is the indentation displacement in the sample at the peak of each unload. Once the contact radius is estimated, the values of indentation stress and indentation strain can be computed using Equations (7) and (8). It should be noted that each unloading segment in these protocols results in the estimation of one point on the microindentation stress-strain curve. Consequently, multiple load-unloading cycles are needed to produce a reasonable indentation stress-strain curve. Twenty unloading segments were incorporated in each microindentation test reported in this study. An example microindentation stress-strain curve extracted in our study is shown in Figure 3f.

\section{Results and Discussion}

Example SEM and EBSD images obtained from the DP steel samples produced in this work are presented in Figure 1. SEM images reveal the presence of martensite islands in a matrix of ferrite grains. For the selected low carbon alloy with carbon content in the range of $0.15-0.17 \mathrm{wt} . \%$, samples quenched from $750{ }^{\circ} \mathrm{C}, 780^{\circ} \mathrm{C}$, and $810^{\circ} \mathrm{C}$ were expected to produce $23-27 \mathrm{vol} \%$, 35-40 vol. \%, and 56-64 vol.\% of martensite, respectively. These predicted values were confirmed from several large EBSD scans obtained at different locations on each sample (presented in Table 2). In the EBSD maps, multicolored regions are ferrite grains whose lattice orientations have been mapped out with a $1 \mu \mathrm{m}$ spatial resolution and martensite regions are colored black based on low IQ (image quality) compared to the ferrite regions. As seen from the phase diagram in Figure 1, quenching from a higher intercritical annealing temperature will result in a higher volume fraction of lower carbon content martensite in the microstructure. Some prior studies have shown the significant effect of carbon content on the hardness of the martensite by systematically changing C content in the tested materials [100,101]. As already mentioned, the protocols used in prior literature using sharp indenters result in high variances between different studies (see Table 1). In the present work, we employed the spherical indentation stress-strain 
protocols that have been shown to produce reliable and highly reproducible values for indentation yield strengths at multiple material length scales.

Table 2. Summary of the microindentation measurements obtained in this study. The martensite volume fractions were estimated from large EBSD scans collected on each sample.

\begin{tabular}{ccccc}
\hline Sample Code & $\begin{array}{c}\text { Martensite Volume } \\
\text { Fraction (\%) }\end{array}$ & $\begin{array}{c}\text { Average Elastic } \\
\text { Modulus (GPa) }\end{array}$ & $\begin{array}{c}\text { Average } \\
\text { Indentation Yield } \\
\text { Strength (MPa) }\end{array}$ & $\begin{array}{c}\text { Contact Area } \\
\text { Diameter at Yield } \\
\text { Point }(\mu \mathrm{m})\end{array}$ \\
\hline $750-00-000$ & 25.4 & $174.5 \pm 25.3$ & $899.5 \pm 62.9$ & $284.6 \pm 14.0$ \\
\hline $750-05-170$ & 27.5 & $193.4 \pm 23.3$ & $950.4 \pm 29.7$ & $333.4 \pm 26.4$ \\
\hline $750-10-170$ & 23.5 & $200.9 \pm 22.3$ & $1100.9 \pm 130.3$ & $352.4 \pm 23.0$ \\
\hline $780-00-000$ & 34.8 & $216.8 \pm 23.3$ & $1097.7 \pm 41.6$ & $331.4 \pm 29.6$ \\
\hline $780-05-170$ & 35.3 & $209.6 \pm 15.4$ & $1299.4 \pm 68.7$ & $356.2 \pm 35.4$ \\
\hline $780-10-170$ & 38.9 & $201.9 \pm 16.7$ & $1336.3 \pm 69.5$ & $362.6 \pm 28.4$ \\
\hline $810-00-000$ & 56.3 & $188.5 \pm 14.7$ & $1168.6 \pm 186.8$ & $306.6 \pm 21.8$ \\
\hline $810-05-170$ & 59.6 & $219.2 \pm 14.5$ & $1340.4 \pm 130.9$ & $338.6 \pm 20.4$ \\
\hline $810-10-170$ & 60.4 & $207.6 \pm 9.7$ & $1506.5 \pm 132.3$ & $361.0 \pm 30.2$ \\
\hline
\end{tabular}

\subsection{Microindentation and Results}

About 10-15 microindentation tests were conducted at randomly selected locations on each of the nine differently processed samples. From each microindentation test, values of Young's modulus and indentation yield strength (defined using a $0.2 \%$ plastic strain offset as shown in Figure $3 \mathrm{f}$ ) were extracted; these are summarized in Figure 4 and Table 2. It is seen from Table 2 that increasing the intercritical annealing temperature increased the bulk indentation yield strength of the sample (e.g., the indentation yield strength increased by $\sim 30 \%$, from $899.5 \pm 62.9 \mathrm{MPa}$ for sample 750-00-000 to $1168.6 \pm 186.8 \mathrm{MPa}$ for sample 810-00-000). In addition, the same trend can be detected when cold work and bake hardening processes are applied. The indentation yield strength increased by 17-29\%, when $10 \%$ thickness reduction and bake hardening were applied, when compared to the quenched sample without bake hardening. As a specific example, the indentation yield strength increased from 1168.6 \pm 186.8 MPa for sample 810-00-000 to 1506.5 \pm 109.5 MPa for sample 810-10-170.

In the indentation tests, the contact diameter $(2 a)$ provides an estimate of the length scale of the material under the indenter that has been subjected to significant plastic deformation (see Figure 2). The estimated contact diameters at the indentation yield estimated by Hertz's theory (Equation (12)) are summarized in Table 2. As an example, the estimated contact diameter at the yield point for one of the microindentations conducted in this study is shown as a blue dashed circle on a sample micrograph in Figure 4d. Furthermore, the primary deformation zone under the indenter is estimated to extend to about $2.4 a$ underneath the indenter [62]. It is therefore estimated that the indentation zone at yield is approximately $300 \mu \mathrm{m}$ in diameter and $400 \mu \mathrm{m}$ in depth for the samples studied here. The primary indentation zone at yield in the microindentation tests reported in this study contained $\sim 300-700$ grains (based on an approximate grain size of $30 \mu \mathrm{m}$ ). Therefore, the microindentation measurements presented here can be assumed to reflect the bulk (macroscale) properties of the samples.

The microindentation measurements presented here compare well with the values reported in the literature for samples with similar compositions and processing histories. The reported values of Young's moduli for similar DP steels are in the range of 170-210 GPa [102-104]. Furthermore, tensile yield strengths have been reported in the range of 345-482 MPa [24,105-107], 413-622 MPa [24,106,108,109], and 520-670 MPa [110-113] for the intercritical annealing temperatures of $750{ }^{\circ} \mathrm{C}, 780{ }^{\circ} \mathrm{C}$, and $810{ }^{\circ} \mathrm{C}$, respectively. Considering a scaling factor of 2 (see Patel et al. [97]) for converting indentation yield 
strength to the tensile yield strength, the values reported in Table 2 are in good agreement with the values reported in the literature.
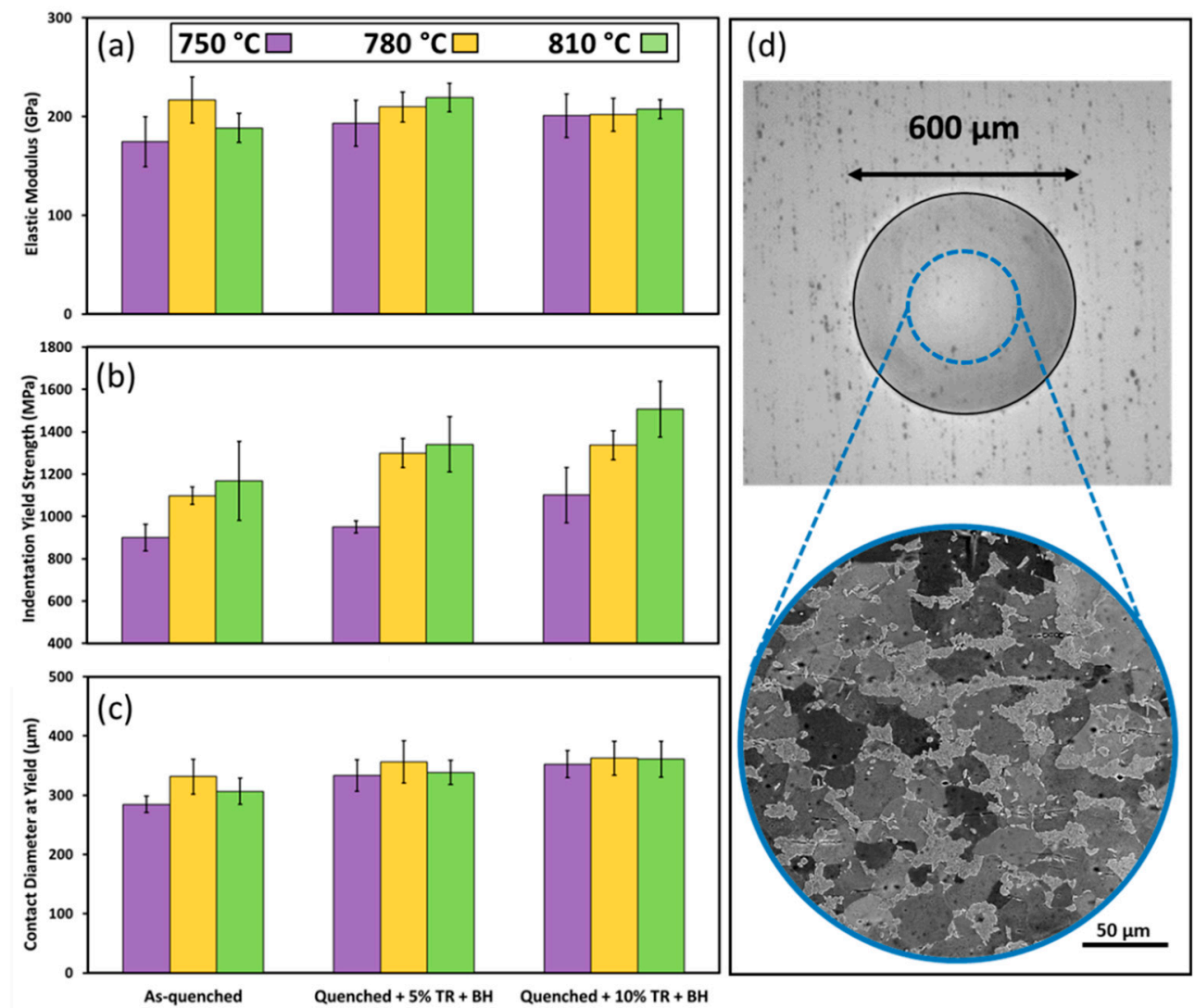

Figure 4. (a-c) Histograms summarizing the extracted values of Young's moduli, indentation yield strengths, and the contact diameters at yield from microindentation tests on samples produced by different processing histories. The different processing histories included intercritical annealing at $750{ }^{\circ} \mathrm{C}, 780^{\circ} \mathrm{C}$, and $810^{\circ} \mathrm{C}$ followed by quenching. The samples were then cold-worked (5\% and $\left.10 \%\right)$ and bake hardened $(\mathrm{BH})$. (d) An optical micrograph and BSE image showing the indentation size at yield as a dashed blue circle.

The results from the microindentation measurements raise two important questions. First, when the martensite volume fraction doubled (from $\sim 25 \%$ to $\sim 58 \%$ ), the indentation yield strength increased only by $\sim 30 \%$. Given the expected high strength of the martensite compared to the ferrite, one should expect a bigger increase in the macroscale yield strength. Second, the bake hardening produced an increase in the strength by $1729 \%$. Given that the martensite volume fraction remains the same during the bake hardening process, and a possible reduction of the martensite strength during the bake hardening step, the physical processes responsible for this significant increase in the strength are not clear. These questions can be addressed by measuring the mechanical responses at the length scale of the constituent phases using the nanoindentation protocols described earlier.

\subsection{Nanoindentation and Results}

As discussed earlier, DP steel microstructures exhibit rich heterogeneity over a hierarchy of material length scales (see Figure 5). At the mesoscale, these include different thermodynamic phases with different crystal structures (Figure 5a,b) and local differences in chemical compositions (especially in carbon and alloying elements). At lower length scales, there exist other heterogeneities within each phase. In martensite, one encounters grains of different crystal orientations, low and high angle grain/phase boundaries, and possibly small carbides (Figure 5c,d). In ferrite, one observes heavily 
deformed ferrite regions, especially at the vicinity of the ferrite/martensite interface (Figure 5e). Studies of the mechanical responses of DP steels at different spatial resolutions are critically needed to obtain new physical insights into the overall response of the alloy. Given the heterogeneity involved, it is also important to perform multiple measurements at randomly selected locations to obtain statistically meaningful data.

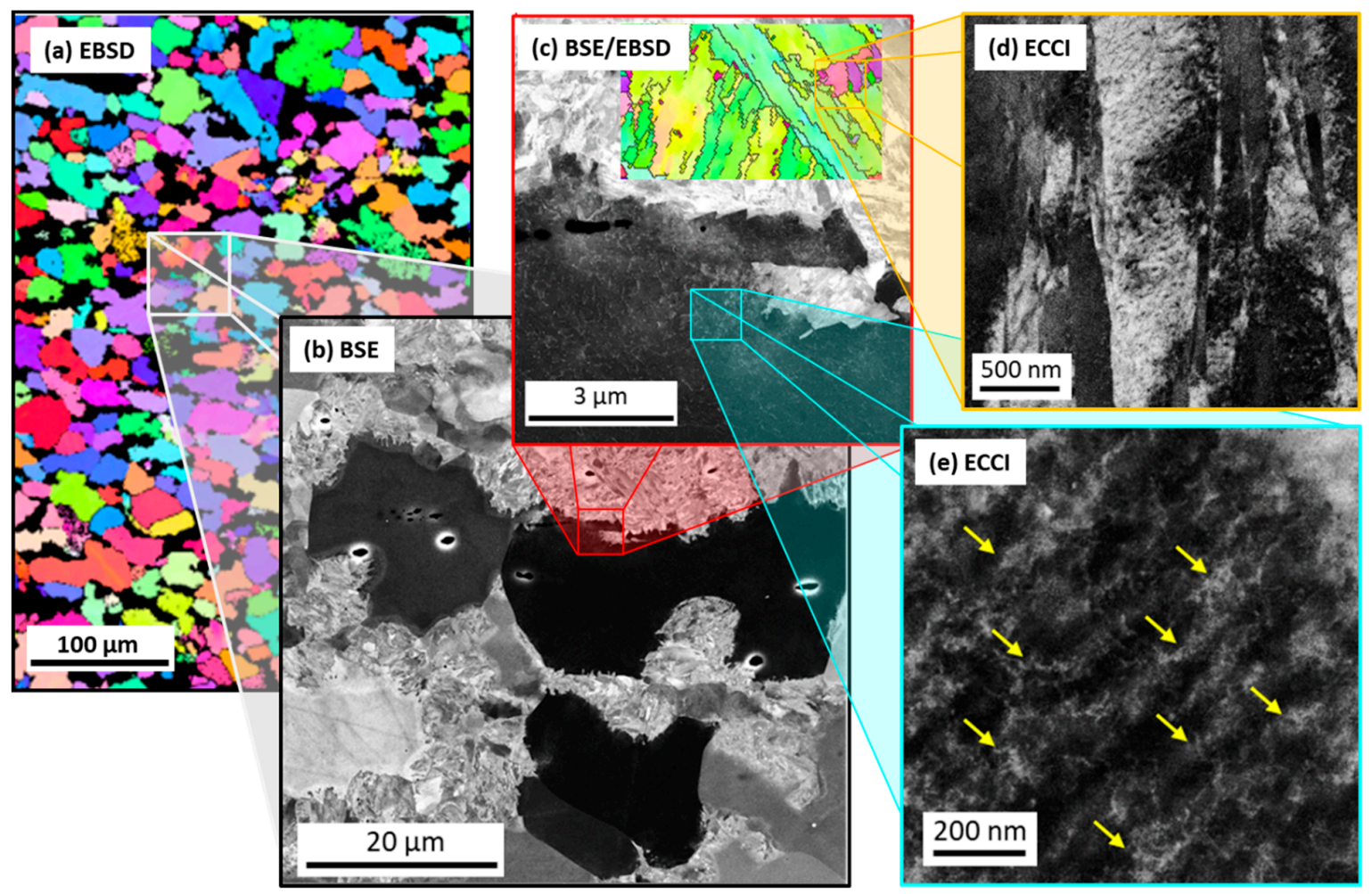

Figure 5. A sampling of microstructures of the sample 810-00-000 using different techniques showing the heterogeneous and hierarchical microstructure of DP steel at different length scale. (a) An EBSD map showing several ferrite grains (in different colors) and martensite regions (in black color). (b) A BSE-SEM image of the microstructure at slightly higher magnification shows details of the martensite regions that contain blocks of martensite reflected with high contrast inside each island. (c) The magnified image shows more detail at the martensite/ferrite interface. The colored image is a high-resolution EBSD map on the martensite island showing the orientations of martensite blocks. (d,e) High-resolution maps of the martensite and ferrite regions obtained using the electron channeling contrast imaging (ECCI) technique. The ECCI micrograph on the martensite shows a highly dislocated structure. The ECCI micrograph on the ferrite grain were collected at the vicinity of the martensite/ferrite interface, where a higher dislocation network (highlighted by yellow arrows) was observed compared to the regions in the center of the ferrite grains.

In this study, we investigated the local mechanical responses in the DP steel samples using two different spherical indenter tips of radii $1 \mu \mathrm{m}$ and $16 \mu \mathrm{m}$, respectively. In prior work on fully martensitic Fe-Ni alloys [57], the contact diameters in indentations conducted with a $1 \mu \mathrm{m}$ radius tip were estimated to be $~ 100-150 \mathrm{~nm}$ at yield. The primary deformation zone in these indentations is likely to have included only a handful of martensite laths, as their thickness was reported to be in the range of 50-200 nm [114,115]. Furthermore, it was reported [57] that the measured average indentation yield strengths with both the $1 \mu \mathrm{m}$ and the $16 \mu \mathrm{m}$ tip radii were in good agreement with each other, while the standard deviations were smaller for the measurements with the $16 \mu \mathrm{m}$ tip. This is reasonable because one would expect a larger number of martensite laths in the primary indentation zone with the larger indenter tip. For the DP steel samples studied here, it was observed that the martensite indentation yield strengths measured with the $16 \mu \mathrm{m}$ tip were systematically lower compared to the measurements with 
the $1 \mu \mathrm{m}$ tip. For example, for the case of sample 810-10-170, the measured values of the Young's modulus and indentation yield strength on martensite regions using the $16 \mu \mathrm{m}$ tip radius were $179.5 \pm 10.6 \mathrm{GPa}$ and $2.15 \pm 0.26 \mathrm{GPa}$, respectively. However, the values of Young's modulus and indentation yield strength measured using the $1 \mu \mathrm{m}$ tip radius were $241.4 \pm 20.3 \mathrm{GPa}$ and $3.0 \pm 0.46 \mathrm{GPa}$, respectively. This observation is particularly surprising as neither the fully martensitic alloy [57] nor other metals we have previously tested using similar protocols [57,59-61] showed any strong effects of indenter tip size on the measured indentation yield strengths. We believe that the lower values measured with the $16 \mu \mathrm{m}$ tip are a consequence of the fact that the stress fields under the indenter extend far beyond the primary indentation deformation zone (defined to be of the order of the contact diameter). Indeed, finite element simulations conducted in prior studies from our research group [62] have revealed that the stress field underneath the indenter can extend as far as $10 a$ to $15 a$ before reducing to negligible levels. This is also the primary reason why the existing Vickers, Knoop, and Rockwell hardness standards [116,117] recommend that the thickness of the tested sample should be at least 10 times the indentation depth to minimize any influence of the substrate on the measured indentation properties. In the DP steel samples studied here, the martensite particles are surrounded by soft ferrite grains. Given the typical martensite particle size of $10 \mu \mathrm{m}$ (see Figure 1) the average thickness of the martensite region in the indentation direction is likely to be only $\sim 5 \mu \mathrm{m}$ (i.e., if one assumes that half the particle has been polished to reveal the martensite region on the sample). Based on the above discussion, we estimate that the stress field under the $16 \mu \mathrm{m}$ tip in the indentations on martensite regions is likely to extend to about $10 \mu \mathrm{m}$, which is significantly larger than the expected remaining thickness of the martensite plate at the indentation site in our measurements. The above discussion is schematically illustrated in Figure 6 where the indentation primary zone (volume of material underneath indentation where the majority of plasticity occurs) is highlighted in red and the extent of the indentation stress field is highlighted in yellow for the $1 \mu \mathrm{m}$ and $16 \mu \mathrm{m}$ tip radii on a BSE-SEM image of a typical sample studied in this work. Although the primary indentation zone with the $16 \mu \mathrm{m}$ tip is expected to lie within the martensite region, the corresponding stress field should be expected to extend into the soft ferrite region underneath the indented martensite particle. For the indentations performed with the $1 \mu \mathrm{m}$ tip radius, both the primary indentation zone and the indentation stress field are much more likely to lie within the martensite phase. It is also important to note that the local stresses in the primary indentation zone in the martensite are expected to be high because of the higher hardness of the martensite phase. Indeed, the softer ferrite regions at the martensite-ferrite boundary under the $16 \mu \mathrm{m}$ tip indenter might even experience some plastic deformation. Because of the factors discussed above, we believe that the lower values of Young's moduli and the indentation yield strengths measured on the martensite regions with the $16 \mu \mathrm{m}$ tip are largely a consequence of the softer ferrite underneath the indented martensite particles. Consequently, only the indentation measurements on martensite regions obtained using the $1 \mu \mathrm{m}$ tip are reported in this work.

For the nanoindentation on ferrite grains, it was observed that the measurements obtained with the $1 \mu \mathrm{m}$ tip exhibited high levels of variance within a single sample. We believe this is because of the heterogeneously deformed regions present in the ferrite grains (see Figure $5 b, c, e$ ). In particular, higher levels of dislocation density have been noted in the vicinity of the martensite/ferrite interface $[1,11,118,119]$. To obtain reliable measurements of indentation properties from the ferrite regions, we identified relatively large ferrite grains and used the $16 \mu \mathrm{m}$ tip. The softer ferrite limits the stress values in the primary indentation zone, further mitigating any influence of the harder martensite regions below the indented ferrite grains. 


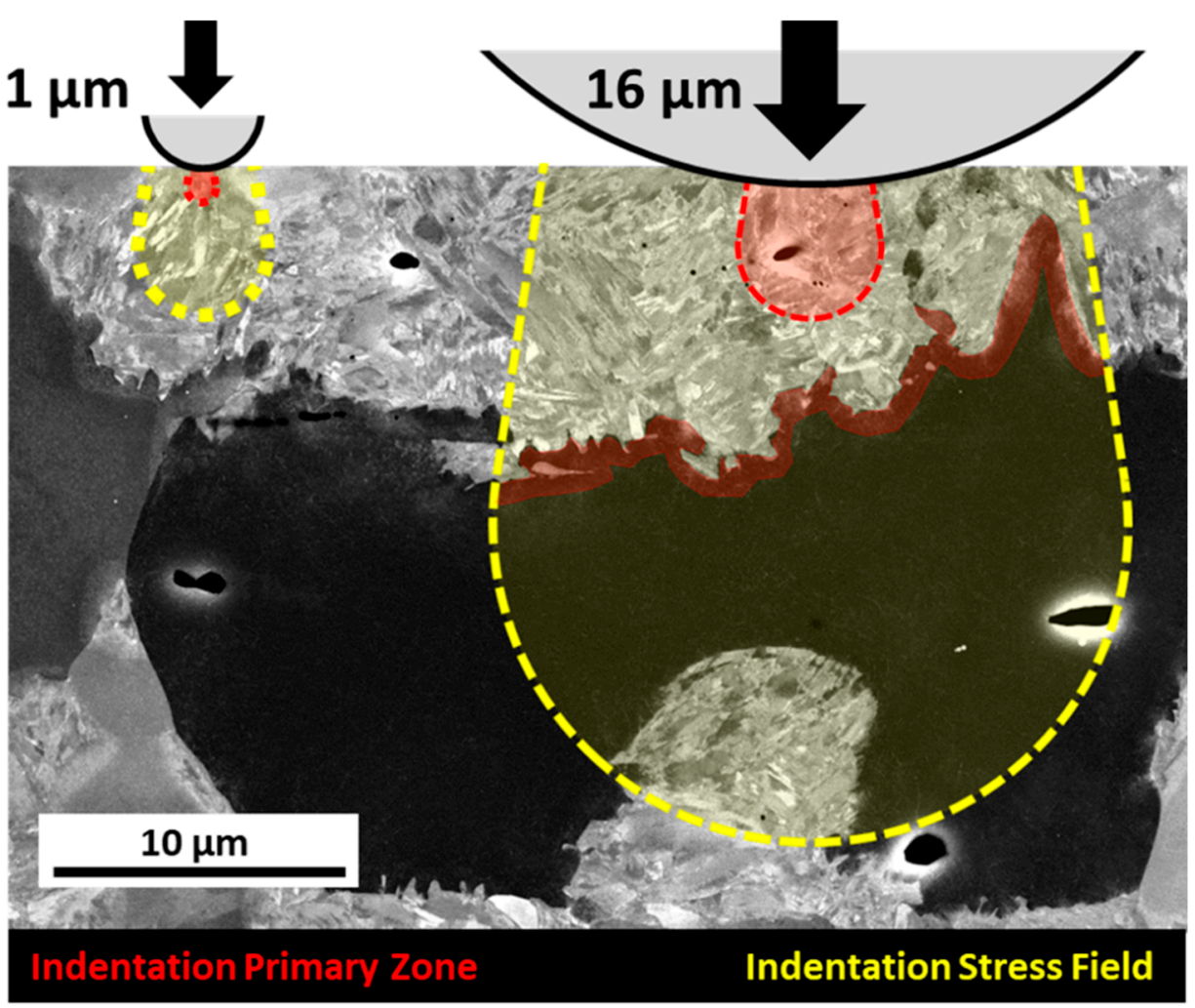

Figure 6. Schematic illustration of the primary indentation deformation zone (volume of the material where the majority of deformation occurs) and the extent of the indentation stress field for both the $1 \mu \mathrm{m}$ and $16 \mu \mathrm{m}$ tip radii, superimposed on a representative BSE-SEM image of DP steel studied in this work.

Examples of the indentation load-displacement and indentation stress-strain curves obtained in this work are presented in Figure 7 for both the martensite and ferrite regions in sample 750-00-000. As discussed before, the transition from the elastic regime to the elastic-plastic regime is clearly discernable in the indentation plots. The values of Young's modulus for the martensite regions were found to be higher compared to those measured in the ferrite regions (in Figure 7, these values were $226 \mathrm{GPa}$ and $176 \mathrm{GPa}$, respectively). The indentation yield strength is usually defined using a 0.002 plastic strain offset. This protocol has been used extensively in prior studies [54-59], especially in the absence of pop-in events. A pop-in is identified as a sudden jump in the indentation displacement at a roughly constant load (the tests are performed in load control) and appears as a strain burst in the indentation stress-strain curves (see the measurement for the ferrite region in Figure 7). Pop-in events have been observed extensively in previous work [54,120-125] and were attributed to the difficulty of activating dislocation sources in the very small primary indentation zone. These pop-ins make it difficult to accurately estimate the indentation yield strength. In prior work $[54,55,58,61]$, it was shown that a back-extrapolation method (see Figure 7) provides a reasonable estimate of the indentation yield strength in such cases. This same strategy was employed in the present work.

As discussed earlier, the intercritical annealing temperature and bake hardening steps are the critical processing steps in manufacturing DP steels. The effect of the quenching temperature on the strength of the individual ferrite and martensite regions was studied using samples 750-00-000, 780-00-000, and 810-00-000. As already mentioned, these samples produce martensite regions with significant differences in C content, offering an opportunity to quantitatively study the effect of $\mathrm{C}$ content on the yield strength of martensite. Comparing the nanoindentation measurements in the martensite and ferrite regions in samples $810-00-000$ and 810-10-170 will provide quantitative insights into how bake hardening influences the yield strengths of these constituents. About 25-30 
nanoindentation tests were performed in centers of randomly selected, relatively large, ferrite, and martensite regions on each sample identified above.
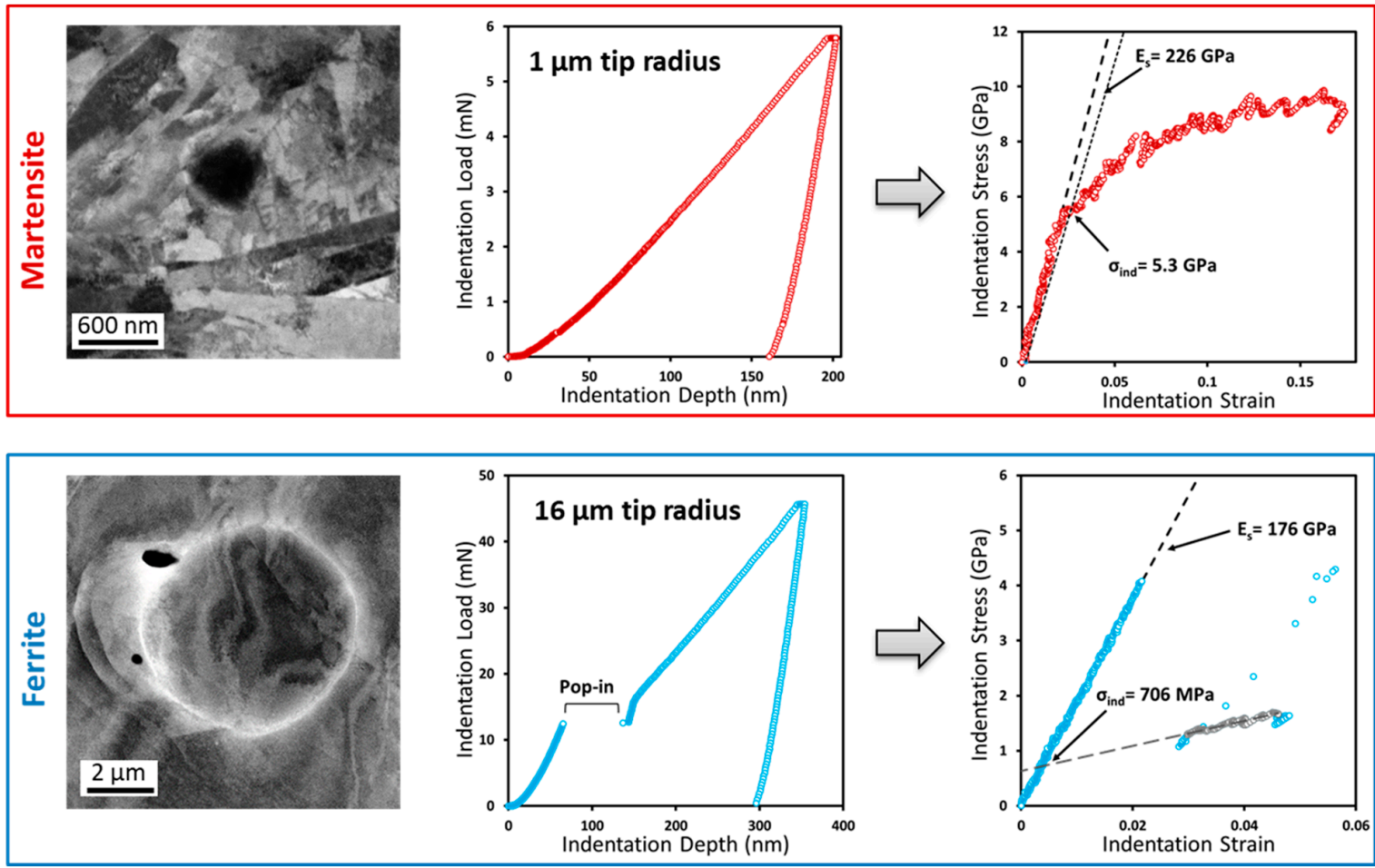

Figure 7. Example load-displacement, indentation stress-strain curves, and SEM micrographs of residual indentations from the martensite (top in red color) and ferrite (bottom in blue color) regions.

Figure 8 summarizes all of the indentation stress-strain curves extracted from the tests conducted on the four samples identified above. For reasons already discussed, the $1 \mu \mathrm{m}$ tip was used on martensite regions, the $16 \mu \mathrm{m}$ tip was used on ferrite regions, and the $6.35 \mathrm{~mm}$ tip (microindentation) was used for evaluating the bulk properties of the samples. The Young's moduli for martensite and ferrite regions were found to be significantly different from each other in these samples. The Young's modulus in the martensite regions varied in the 220-252 GPa range, while it varied in a much narrower range of 171-179 GPa for the ferrite regions. The larger variance in the extracted values of Young's moduli for the martensite regions can be attributed to the fact that the smallest tip ( $1 \mu \mathrm{m}$ radius) was used in these studies. The limited number of laths in the indentation zone combined with the expected significant effect of the martensite lattice orientation on the indentation measurements can explain the observed larger variance. Notwithstanding the larger variance, the measurements clearly indicate that the Young's modulus of the martensite is higher compared to the Young's modulus of the ferrite.

The average indentation yield strength ( \pm one standard deviation) is shown as a colored band on each plot in Figure 8. The indentation yield strengths measured from all four samples mentioned earlier are summarized in Figure 9. As expected, the measured variances decrease with an increasing indenter tip radius. This is because the larger indenter tips provide averaged responses over larger material volumes. Figure 9 also presents percentage changes in the indentation yield strengths measured in the martensite and ferrite regions in samples 780-00-000 and 810-00-000 using sample 750-00-000 as the baseline. It is seen that the bulk indentation yield strength increased by $27 \%$ when the intercritical annealing temperature was increased from $750{ }^{\circ} \mathrm{C}$ to $810{ }^{\circ} \mathrm{C}$. As already noted, there is a significant increase in the martensite volume fraction (25\% for 750-00-000 samples and 56\% for 810-00-000 samples; see Table 2). Figure 9 also shows that the martensite yield strength has decreased by $\sim 37 \%$ in the 810-00-000 sample, compared to the 750-00-000 sample. This reduction is attributed to the decrease in the $\mathrm{C}$ content in the martensite. Based on the Fe-C phase diagram, the $\mathrm{C}$ content in martensite $\left(C_{M}\right)$ 
quenched from $750{ }^{\circ} \mathrm{C}$ is expected to be $\sim 0.58 \mathrm{wt} . \%$, while it is $\sim 0.26 \mathrm{wt} . \%$ for the sample quenched at $810^{\circ} \mathrm{C}$. The strong influence of $\mathrm{C}$ content on the martensite strength has been also discussed in prior studies $[57,100,101,126]$. Notably, the carbon content in the ferrite phase is expected to exhibit only a negligible increase, which does not appear to influence significantly the indentation yield strength of the ferrite.
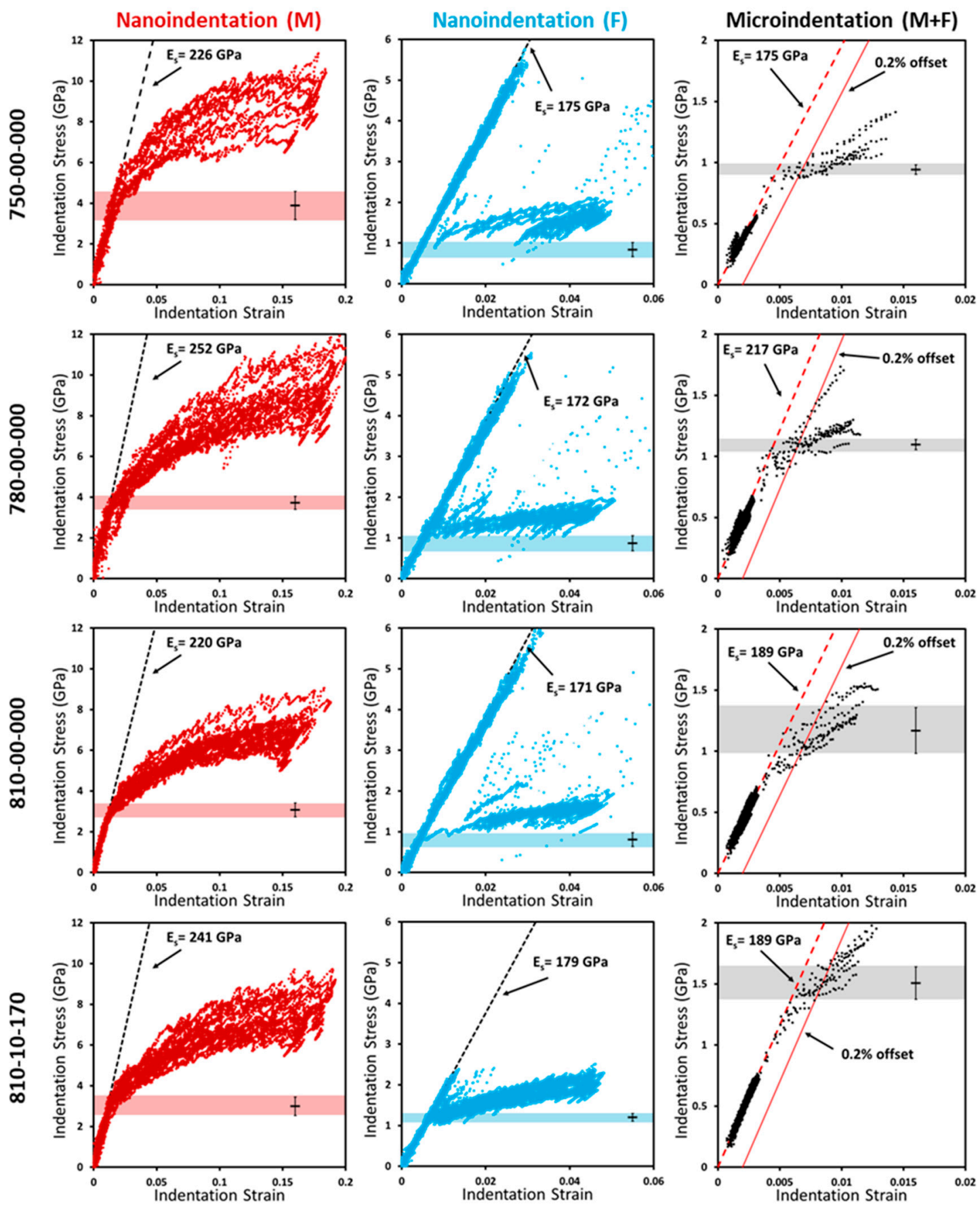

Figure 8. Multiple indentation stress-strain measurements at different lengths scales on samples 750-00-000, 780-00-000, 810-00-000, and 810-10-170. The left column shows the indentation stress-strain curves from multiple tests on martensite using the $1 \mu \mathrm{m}$ tip radius. The center column shows the indentation stress-strain curves from multiple tests on ferrite grains using the $16 \mu \mathrm{m}$ tip radius. The right column shows the micro-indentation stress-strain curves from multiple tests using the $6.35 \mathrm{~mm}$ tip radius. The highlighted horizontal bands inside each plot show the average values of the indentation yield strength and their variations. 


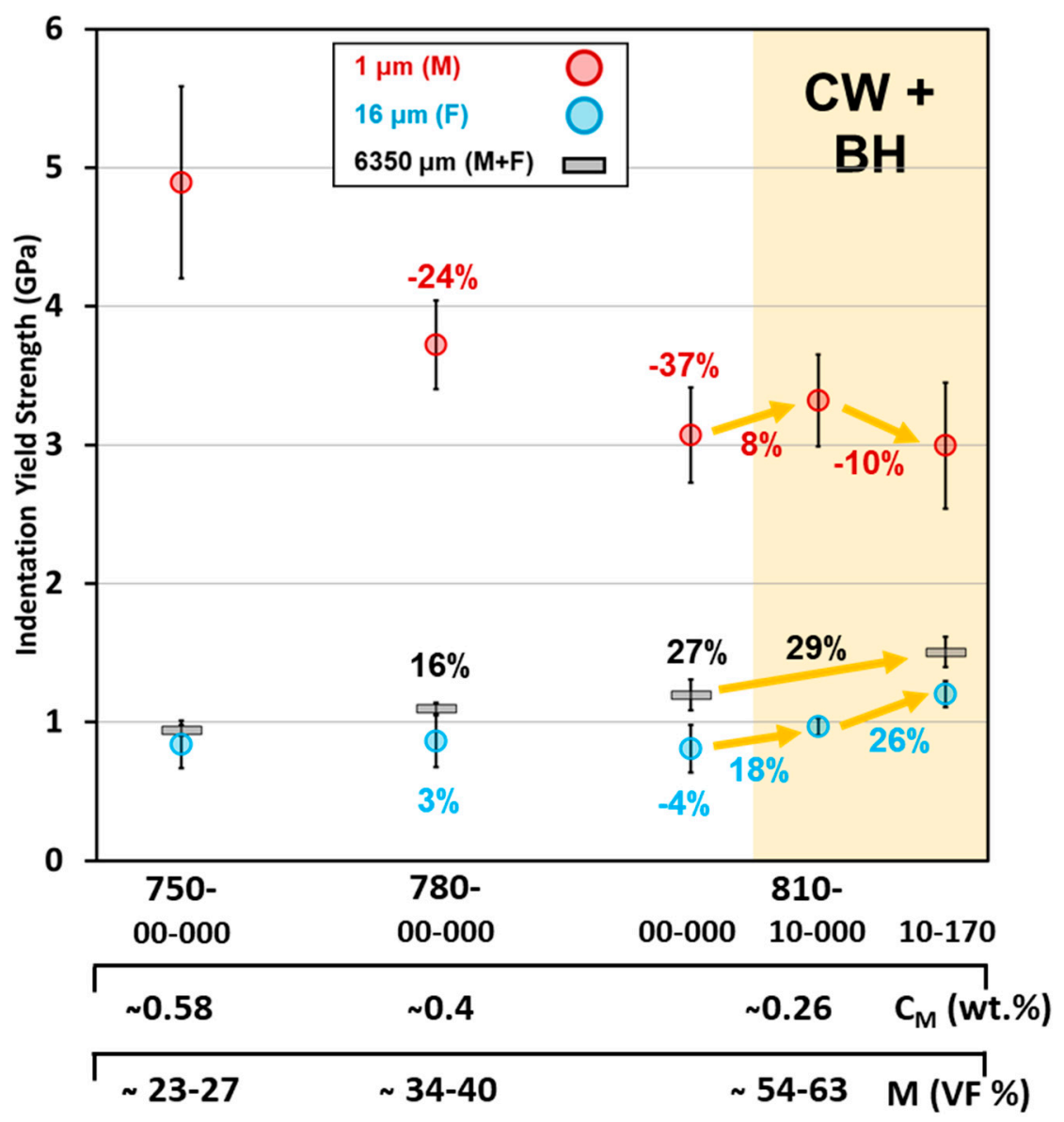

Figure 9. Extracted indentation yield strengths for samples 750-00-000, 780-00-000, 810-00-000, 810-10-000, and 810-10-170 at different length scales in martensite (M) and ferrite (F) regions. Bulk measurements $(\mathrm{M}+\mathrm{F})$ are obtained using microindentation tests. The numbers in the white region show the percentage changes with respect to the values from sample 750-00-000. The numbers in the yellow box show the percentage changes during the cold work and tempering steps in the bake hardening process for the 810-10-170 sample. The percentage of the martensite volume fractions and the carbon concentration in martensite are estimated from the $\mathrm{Fe}-\mathrm{C}$ phase diagram in Figure 1.

Comparing the measurements on the martensite regions in sample 810-00-000 with those on sample 810-10-170 in Figure 9, it is seen that the average indentation yield strength decreased by a negligible amount $(\sim 2.5 \%)$ after the bake hardening step. This observation is consistent with other studies where it was reported that martensite hardness remains unchanged when the bake hardening temperature is kept below $\sim 250^{\circ} \mathrm{C}$ [126-130]. To separate the effects of hardening during cold work and softening by tempering in the bake hardening process, another sample was prepared right after cold work and without applying bake hardening. This sample is labeled as 810-10-000 in Figure 9. The indentation results show an increase of $8 \%$ in the indentation yield strength of the martensite regions during the cold work, followed by $10 \%$ softening during the tempering process in the bake hardening step. It was observed that during the bake hardening process, carbon atoms diffuse out of martensite islands into low carbon content ferrite grains and tend to build a carbon Cottrell atmosphere around dislocation cores, which immobilizes the dislocations [11,34,131-133]. Figure 10 shows an example of a ferrite grain surrounded by martensite islands in sample 810-10-170. As seen in Figure 10a, the ferrite grain has a highly contrasted matrix, which makes it very difficult to identify its interface with neighboring martensite islands. The ferrite grain boundaries are highlighted by dashed lines colored in yellow in this figure. Higher resolution images from the ECCI technique (see Figure 10b,c) reveal the presence of highly dense dislocation networks inside the contrasting regions. Few dislocations are highlighted by 
blue arrows in Figure 10c, which appear as white contrast on the black-background matrix. As shown in the highlighted yellow area in Figure 9, the indentation yield strength of ferrite increased by $50 \%$ when cold work and bake hardening were applied (from $0.81 \pm 0.17 \mathrm{GPa}$ for sample 810-00-000 to $1.2 \pm 0.09$ for sample 810-10-170). Indeed, one should expect an increase in the yield strength of the ferrite due to the imposed cold work. However, ferrite exhibits a low work hardening rate and the applied cold work only increased the indentation yield strength by $18 \%$ in the sample $810-10-000$. A further $26 \%$ increase was observed in the indentation yield strengths in the ferrite between the samples 810-10-000 and 810-10-170, which is attributed to static aging resulting from the pinning of the dislocations by the diffused carbon atoms from the martensite.
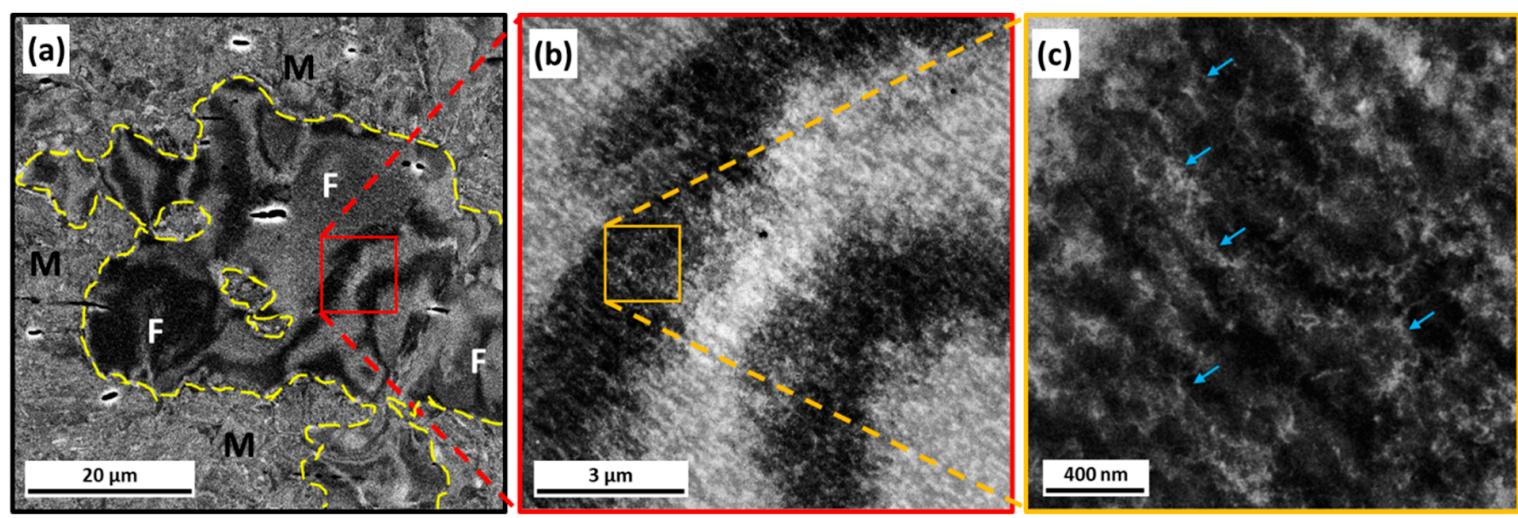

Figure 10. (a) BSE-SEM micrograph obtained on sample 810-10-170. The high contrast in both ferrite and martensite makes it difficult to identify their interface. For this purpose, each phase is labeled as martensite (M) or Ferrite (F) and their interfaces are highlighted as yellow dashed lines. (b) The ECCI technique at higher magnifications reveals a dense network of dislocations inside a ferrite grain. (c) The dislocation cores can be distinguished at sub-micron magnifications (see blue arrows).

Indirect evidence of a significant role of dislocation pinning on the strengthening of the ferrite can be found in indentation results. All the collected indentation load-displacement curves from ferrite regions on sample 810-10-170 revealed significant pop-in events while no pop-ins were observed from ferrite regions on sample 810-10-000. Figure 11a shows an example of a $3.6 \mathrm{~nm}$ pop-in (highlighted by a red arrow) in the indentation depth range of 30-40 $\mathrm{nm}$. In prior studies using the spherical indentation protocols described earlier, pop-ins were observed exclusively on fully-annealed metal samples when small indenter tips (e.g., a spherical tip with $1 \mu \mathrm{m}$ radius) were utilized [54,122,134-136]. In those studies, pop-ins disappeared after the introduction of small amounts of plastic deformation [136]. Therefore, in the prior studies, it was concluded that the pop-ins were a consequence of the difficulty of activating dislocation sources within the primary indentation deformation zone [54,120-122,124,125]. In the present work, the lack of pop-ins in the 810-10-000 sample is consistent with the previous observations described above. However, the 810-10-170 sample showed significant pop-ins, even though the ferrite grains have multiple dislocations within the indentation zone size of the $16 \mu \mathrm{m}$ radius tip (see Figure 10). In the indentations performed on ferrite regions in this study, the ratio of the pop-in stress to the back-extrapolated yield strength was found to be $1.63 \pm 0.35$. This means that the initiation of plastic deformation was found to be significantly more difficult than continued plastic deformation after the initial yield. Therefore, the pop-ins observed in the tests reported here on the ferrite regions are attributed to the pinning of dislocations by static aging described earlier. Furthermore, as indentation proceeds, the indentation primary zone expands and encompasses new pinned dislocations. If an insufficient number of mobile dislocations exist inside the indentation primary zone, one should expect the occurrence of additional pop-ins. In our experiments, we often found such additional pop-ins (see the one marked by the orange arrow at the depth of $40 \mathrm{~nm}$ in Figure 11a). Of course, the subsequent pop-ins do not produce as large drops in stresses as the response is averaged over a much larger volume. It is important to note that such additional pop-ins were 
rarely observed in prior studies on fully annealed metal samples $[54,58,61]$ because the dislocation sources are easily established in these samples at the larger indentation zone sizes created after the first pop-in. The presence of these pop-ins in the 810-10-170 and their absence in 810-10-000 provides the strongest direct evidence supporting the hypothesis that the ferrite regions in the DP steels experience a significant amount of dislocation pinning during the bake hardening step.
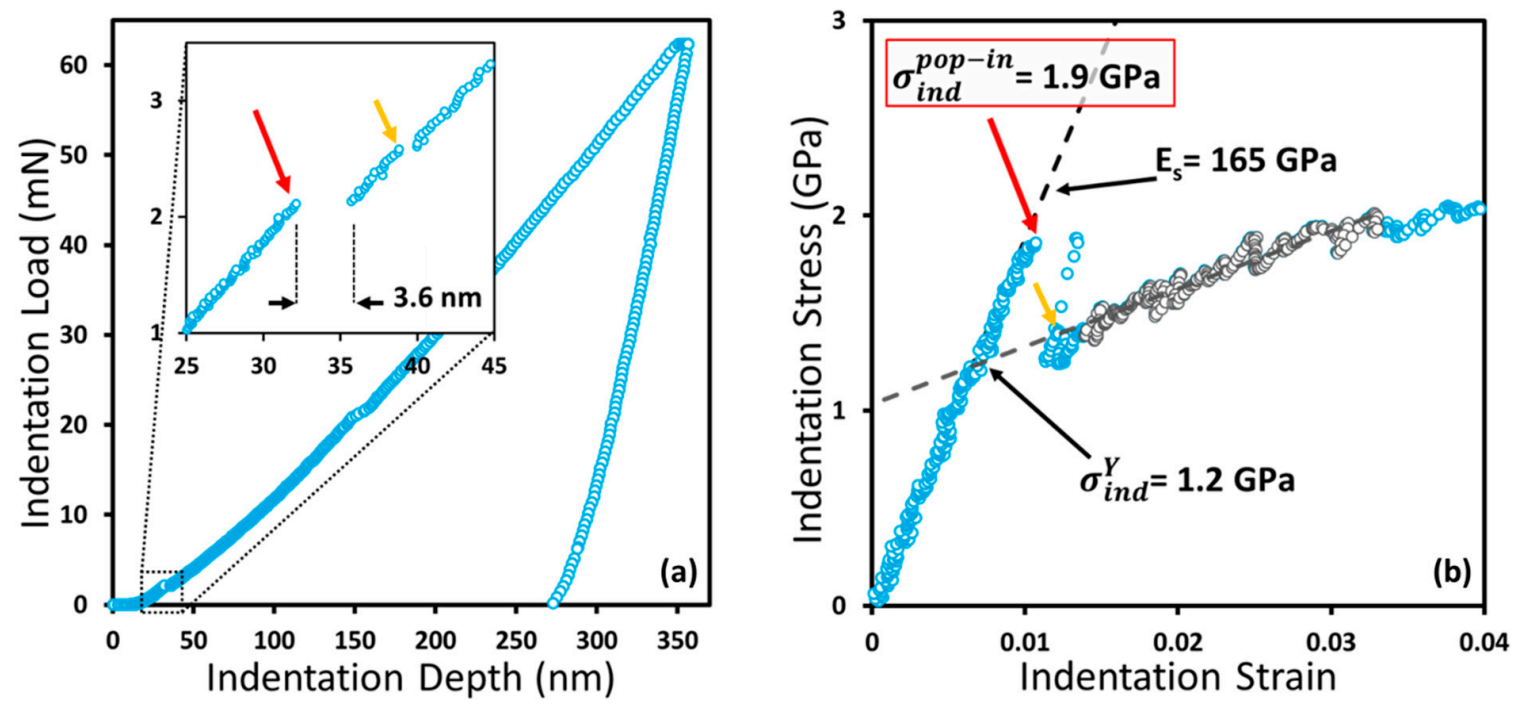

Figure 11. Example (a) load-displacement and (b) indentation stress-strain curves on the ferrite region from sample 810-10-170. The observed pop-in is attributed to the higher stress needed to unpin the dislocations from the carbon atmosphere.

\section{Conclusion}

The mechanical properties of DP steels were investigated at different length scales using spherical indentation stress-strain protocols. A total of nine samples processed with different combinations of intercritical annealing temperatures and different amounts of cold-work in the bake hardening step were studied. Bulk property measurements were carried out using a $6.35 \mathrm{~mm}$ tip radius showed results consistent with the relevant existing tensile data from the literature. However, the spherical indentation protocols used in this study require very small material volumes. An increase of the martensite volume fraction from $25 \%$ to $56 \%$ (for samples quenched from $750{ }^{\circ} \mathrm{C}$ and $810{ }^{\circ} \mathrm{C}$, respectively) resulted in a $27 \%$ increase of the bulk indentation yield strength. Furthermore, the addition of the bake hardening step to the sample subjected to intercritical annealing at $810{ }^{\circ} \mathrm{C}$ produced a further $29 \%$ increase in the indentation yield strength.

Nanoindentation measurements were performed separately on both martensite and ferrite regions to obtain quantitative insights into how the different processing parameters affected their individual properties (at the scale of individual phases). It was first established that the measurements on martensite are best conducted using the $1 \mu \mathrm{m}$ radius indenter tip, while the measurements on ferrite needed the $16 \mu \mathrm{m}$ radius indenter tip for producing the most reliable data. The measurements conducted in this study revealed that the martensite regions exhibited on average a 36\% higher Young's modulus compared to the ferrite regions. Intercritical annealing at $810{ }^{\circ} \mathrm{C}$ instead of at $750{ }^{\circ} \mathrm{C}$ decreased the indentation yield strength of martensite by $\sim 37 \%$, while the indentation yield strength of the ferrite regions remains more or less unchanged. Cold work and bake hardening of the sample intercritically annealed at $810^{\circ} \mathrm{C}$, increased the indentation yield strength in the ferrite regions by $50 \%$ without a significant change in the indentation yield strength of the martensite. The effects of cold work and tempering treatments employed in bake hardening were investigated. The results showed that the cold work increased the indentation yield strength of both phases, while the tempering treatment softened the martensite and hardened the ferrite. Most importantly, the nature of the pop-ins observed in the 
nanoindentations performed on the ferrite regions suggested that the increase in the indentation yield strength during bake hardening can be attributed to the pinning of dislocations by the diffused carbon.

Author Contributions: A.K. and S.R.K. conceived and designed the experiments; A.K. and C.M.C. performed the experiments; A.K. analyzed the data; A.K. and S.R.K. wrote the paper. All authors have read and agreed to the published version of the manuscript.

Funding: The authors gratefully acknowledge support from the National Science Foundation through the funding grant 1761406.

Conflicts of Interest: The authors declare no conflict of interest-exists.

\section{References}

1. Tasan, C.C.; Diehl, M.; Yan, D.; Bechtold, M.; Roters, F.; Schemmann, L.; Zheng, C.; Peranio, N.; Ponge, D.; Koyama, M.; et al. An Overview of Dual-Phase Steels: Advances in Microstructure-Oriented Processing and Micromechanically Guided Design. Annu. Rev. Mater. Res. 2015, 45, 391-431. [CrossRef]

2. Bian, J.; Mohrbacher, H.; Zhang, J.-S.; Zhao, Y.-T.; Lu, H.-Z.; Dong, H. Application potential of high performance steels for weight reduction and efficiency increase in commercial vehicles. Adv. Manuf. 2015, 3, 27-36. [CrossRef]

3. Fonstein, N. Dual-phase steels. In Automotive Steels: Design, Metallurgy, Processing and Applications; Rana, R., Brat Singh, S., Eds.; Woodhead Publishing: Cambridge, UK, 2017; pp. 169-216.

4. Horvath, C.D. Advanced steels for lightweight automotive structures. In Materials, Design and Manufacturing for Lightweight Vehicles; Mallick, P.K., Ed.; Woodhead Publishing: Cambridge, UK, 2010; pp. 35-78.

5. Rashid, M.S. Dual phase steels. Annu. Rev. Mater. Sci. 1981, 11, 245-266. [CrossRef]

6. Robertson, L.T.; Hilditch, T.B.; Hodgson, P.D. The effect of prestrain and bake hardening on the low-cycle fatigue properties of TRIP steel. Int. J. Fatigue 2008, 30, 587-594. [CrossRef]

7. Ramazani, A.; Bruehl, S.; Gerber, T.; Bleck, W.; Prahl, U. Quantification of bake hardening effect in DP600 and TRIP700 steels. Mater. Des. 2014, 57, 479-486. [CrossRef]

8. Kuang, C.-F.; Zhang, S.-G.; Li, J.; Wang, J.; Li, P. Effect of temper rolling on the bake-hardening behavior of low carbon steel. Int. J. Miner. Metall. Mater. 2015, 22, 32-36. [CrossRef]

9. Waterschoot, T.; Verbeken, K.; de Cooman, B.C. Tempering Kinetics of the Martensitic Phase in DP Steel. ISIJ Int. 2006, 46, 138-146. [CrossRef]

10. Berbenni, S.; Favier, V.; Lemoine, X.; Berveiller, M. A micromechanical approach to model the bake hardening effect for low carbon steels. Scr. Mater. 2004, 51, 303-308. [CrossRef]

11. Timokhina, I.B.; Hodgson, P.D.; Pereloma, E.V. Transmission Electron Microscopy Characterization of the Bake-Hardening Behavior of Transformation-Induced Plasticity and Dual-Phase Steels. Metall. Mater. Trans. 2007, 38, 2442-2454. [CrossRef]

12. Lindqvist, K. Bake Hardening Effect in Advanced High-Strength Steels. Master's Thesis, Chalmers University of Technology, Gothenburg, Sweden, 2013.

13. Kuang, C.-F.; Wang, J.; Li, J.; Zhang, S.-G.; Liu, H.-F.; Yang, H.-L. Effect of Continuous Annealing on Microstructure and Bake Hardening Behavior of Low Carbon Steel. J. Iron Steel Res. Int. 2015, 22, 163-170. [CrossRef]

14. Wang, H.; Shi, W.; He, Y.-L.; Lu, X.-G.; Li, L. Effect of Overaging on Solute Distributions and Bake Hardening Phenomenon in Bake Hardening Steels. J. Iron Steel Res. Int. 2012, 19, 53-59. [CrossRef]

15. Durrenberger, L.; Lemoine, X.; Molinari, A. Effects of pre-strain and bake-hardening on the crash properties of a top-hat section. J. Mater. Process. Technol. 2011, 211, 1937-1947. [CrossRef]

16. Kilic, S.; Ozturk, F.; Sigirtmac, T.; Tekin, G. Effects of Pre-strain and Temperature on Bake Hardening of TWIP900CR Steel. J. Iron Steel Res. Int. 2015, 22, 361-365. [CrossRef]

17. Šebek, M.; Horňak, P.; Zimovčák, P. Effect of Annealing on the Microstructure Evolution and Mechanical Properties of Dual Phase Steel. Mater. Sci. Forum 2014, 782, 111-116. [CrossRef]

18. Asadi, M.; de Cooman, B.C.; Palkowski, H. Influence of martensite volume fraction and cooling rate on the properties of thermomechanically processed dual phase steel. Mater. Sci. Eng. 2012, 538, 42-52. [CrossRef]

19. Vasilyev, A.A.; Lee, H.-C.; Kuzmin, N.L. Nature of strain aging stages in bake hardening steel for automotive application. Mater. Sci. Eng. 2008, 485, 282-289. [CrossRef] 
20. Jeong, W.C. Relationship between mechanical properties and microstructure in a $1.5 \%$ Mn- $0.3 \%$ Mo ultra-low carbon steel with bake hardening. Mater. Lett. 2007, 61, 2579-2583. [CrossRef]

21. Cao, Y.; Ahlström, J.; Karlsson, B. The influence of temperatures and strain rates on the mechanical behavior of dual phase steel in different conditions. J. Mater. Res. Technol. 2015, 4, 68-74. [CrossRef]

22. Kuang, C.F.; Li, J.; Zhang, S.G.; Wang, J.; Liu, H.F.; Volinsky, A.A. Effects of quenching and tempering on the microstructure and bake hardening behavior of ferrite and dual phase steels. Mater. Sci. Eng. 2014, 613, 178-183. [CrossRef]

23. Li, C.-S.; Li, Z.-X.; Cen, Y.-M.; Ma, B.; Huo, G. Microstructure and mechanical properties of dual phase strip steel in the overaging process of continuous annealing. Mater. Sci. Eng. 2015, 627, 281-289. [CrossRef]

24. Hüseyin, A.; Havva, K.Z.; Ceylan, K. Effect of Intercritical Annealing Parameters on Dual Phase Behavior of Commercial Low-Alloyed Steels. J. Iron Steel Res. Int. 2010, 17, 73-78. [CrossRef]

25. Zeytin, H.K.; Kubilay, C.; Aydin, H. Investigation of dual phase transformation of commercial low alloy steels: Effect of holding time at low inter-critical annealing temperatures. Mater. Lett. 2008, 62, 2651-2653. [CrossRef]

26. Demir, B.; Erdoğan, M. The hardenability of austenite with different alloy content and dispersion in dual-phase steels. J. Mater. Process. Technol. 2008, 208, 75-84. [CrossRef]

27. Sudersanan, N.K.P.D.; Aprameyan, S.; Kempaiah, D.U.N. The Effect of Carbon Content in Martensite on the Strength of Dual Phase Steel. Bonfring Int. J. Ind. Eng. Manag. Sci. 2012, 2, 1-4.

28. Seyedrezai, H. Thermo-Mechanical Processing of Dual-Phase Steels and its Effects on the Work Hardening Behaviour. Ph.D. Thesis, Queen's University, Kingston, ON, Canada, 2014.

29. Schemmann, L.; Zaefferer, S.; Raabe, D.; Friedel, F.; Mattissen, D. Alloying effects on microstructure formation of dual phase steels. Acta Mater. 2015, 95, 386-398. [CrossRef]

30. Timokhina, I.B.; Pereloma, E.V.; Ringer, S.P.; Zheng, R.K.; Hodgson, P.D. Characterization of the Bake-hardening Behavior of Transformation Induced Plasticity and Dual-phase Steels Using Advanced Analytical Techniques. ISIJ Int. 2010, 50, 574-582. [CrossRef]

31. Allain, S.Y.P.; Bouaziz, O.; Pushkareva, I.; Scott, C.P. Towards the microstructure design of DP steels: A generic size-sensitive mean-field mechanical model. Mater. Sci. Eng. 2015, 637, 222-234. [CrossRef]

32. Korzekwa, D.A.; Matlock, D.K.; Krauss, G. Dislocation substructure as a function of strain in a dual-phase steel. Metall. Trans. 1984, 15, 1221-1228. [CrossRef]

33. Calcagnotto, M.; Ponge, D.; Demir, E.; Raabe, D. Orientation gradients and geometrically necessary dislocations in ultrafine grained dual-phase steels studied by 2D and 3D EBSD. Mater. Sci. Eng. 2010, 527, 2738-2746. [CrossRef]

34. Cottrell, A.H.; Bilby, B.A. Dislocation theory of yielding and strain ageing of iron. Proc. Phys. Soc. 1949, 62, 49. [CrossRef]

35. Pan, Z.; Gao, B.; Lai, Q.; Chen, X.; Cao, Y.; Liu, M.; Zhou, H. Microstructure and Mechanical Properties of a Cold-Rolled Ultrafine-Grained Dual-Phase Steel. Materials 2018, 11, 1399. [CrossRef]

36. Gerbig, D.; Srivastava, A.; Osovski, S.; Hector, L.G.; Bower, A. Analysis and design of dual-phase steel microstructure for enhanced ductile fracture resistance. Int. J. Fract. 2018, 209, 3-26. [CrossRef]

37. Kundu, J.; Ray, T.; Kundu, A.; Shome, M. Effect of the laser power on the mechanical performance of the laser spot welds in dual phase steels. J. Mater. Process. Technol. 2019, 267, 114-123. [CrossRef]

38. Samei, J.; Zhou, L.; Kang, J.; Wilkinson, D.S. Microstructural analysis of ductility and fracture in fine-grained and ultrafine-grained vanadium-added DP1300 steels. Int. J. Plast. 2019, 117, 58-70. [CrossRef]

39. Zhang, L.; Liang, M.; Feng, Z.; Zhang, L.; Cao, W.; Wu, G. Nanoindentation characterization of strengthening mechanism in a high strength ferrite/martensite steel. Mater. Sci. Eng. 2019, 745, 144-148. [CrossRef]

40. Ghassemi-Armaki, H.; Maaß, R.; Bhat, S.P.; Sriram, S.; Greer, J.R.; Kumar, K.S. Deformation response of ferrite and martensite in a dual-phase steel. Acta Mater. 2014, 62, 197-211. [CrossRef]

41. Seok, M.-Y.; Kim, Y.-J.; Choi, I.-C.; Zhao, Y.; Jang, J.-I. Predicting flow curves of two-phase steels from spherical nanoindentation data of constituent phases: Isostrain method vs. non-isostrain method. Int. J. Plast. 2014, 59, 108-118. [CrossRef]

42. Taylor, M.D.; Choi, K.S.; Sun, X.; Matlock, D.K.; Packard, C.E.; Xu, L.; Barlat, F. Correlations between nanoindentation hardness and macroscopic mechanical properties in DP980 steels. Mater. Sci. Eng. 2014, 597, 431-439. [CrossRef] 
43. Choi, B.-W.; Seo, D.-H.; Yoo, J.-Y.; Jang, J.-I. Predicting macroscopic plastic flow of high-performance, dual-phase steel through spherical nanoindentation on each microphase. J. Mater. Res. 2009, 24, 816-822. [CrossRef]

44. Hayashi, K.; Miyata, K.; Katsuki, F.; Ishimoto, T.; Nakano, T. Individual mechanical properties of ferrite and martensite in Fe-0.16mass\% C-1.0mass\% Si-1.5mass\% Mn steel. J. Alloy. Compd. 2013, 577, S593-S596. [CrossRef]

45. Scott, C.P.; Amirkhiz, B.S.; Pushkareva, I.; Fazeli, F.; Allain, S.Y.P.; Azizi, H. New insights into martensite strength and the damage behaviour of dual phase steels. Acta Mater. 2018, 159, 112-122. [CrossRef]

46. Farivar, H.; Richter, S.; Hans, M.; Schwedt, A.; Prahl, U.; Bleck, W. Experimental quantification of carbon gradients in martensite and its multi-scale effects in a DP steel. Mater. Sci. Eng. 2018, 718, 250-259. [CrossRef]

47. Banadkouki, S.S.G.; Fereiduni, E. Effect of prior austenite carbon partitioning on martensite hardening variation in a low alloy ferrite-Martensite dual phase steel. Mater. Sci. Eng. 2014, 619, 129-136. [CrossRef]

48. Cheng, G.; Zhang, F.; Ruimi, A.; Field, D.P.; Sun, X. Quantifying the effects of tempering on individual phase properties of DP980 steel with nanoindentation. Mater. Sci. Eng. 2016, 667, 240-249. [CrossRef]

49. Zhang, F.; Ruimi, A.; Field, D.P. Phase Identification of Dual-Phase (DP980) Steels by Electron Backscatter Diffraction and Nanoindentation Techniques. Microsc. Microanal. 2016, 22, 99-107. [CrossRef] [PubMed]

50. Li, H.; Gao, S.; Tian, Y.; Terada, D.; Shibata, A.; Tsuji, N. Influence of Tempering on Mechanical Properties of Ferrite and Martensite Dual Phase Steel. Mater. Today Proc. 2015, 2, S667-S671. [CrossRef]

51. Hernandez, V.H.B.; Panda, S.K.; Kuntz, M.L.; Zhou, Y. Nanoindentation and microstructure analysis of resistance spot welded dual phase steel. Mater. Lett. 2010, 64, 207-210. [CrossRef]

52. Azuma, M.; Goutianos, S.; Hansen, N.; Winther, G.; Huang, X. Effect of hardness of martensite and ferrite on void formation in dual phase steel. Mater. Sci. Technol. 2012, 28, 1092-1100. [CrossRef]

53. Weaver, J.S.; Pathak, S.; Reichardt, A.; Vo, H.T.; Maloy, S.A.; Hosemann, P.; Mara, N.A. Spherical nanoindentation of proton irradiated 304 stainless steel: A comparison of small scale mechanical test techniques for measuring irradiation hardening. J. Nucl. Mater. 2017, 493, 368-379. [CrossRef]

54. Pathak, S.; Michler, J.; Wasmer, K.; Kalidindi, S.R. Studying grain boundary regions in polycrystalline materials using spherical nano-indentation and orientation imaging microscopy. J. Mater. Sci. 2012, 47, 815-823. [CrossRef]

55. Pathak, S.; Stojakovic, D.; Kalidindi, S.R. Measurement of the local mechanical properties in polycrystalline samples using spherical nanoindentation and orientation imaging microscopy. Acta Mater. 2009, 57, 3020-3028. [CrossRef]

56. Vachhani, S.J.; Doherty, R.D.; Kalidindi, S.R. Studies of grain boundary regions in deformed polycrystalline aluminum using spherical nanoindentation. Int. J. Plast. 2016, 81, 87-101. [CrossRef]

57. Khosravani, A.; Morsdorf, L.; Tasan, C.C.; Kalidindi, S.R. Multiresolution mechanical characterization of hierarchical materials: Spherical nanoindentation on martensitic Fe-Ni-C steels. Acta Mater. 2018, 153, 257-269. [CrossRef]

58. Weaver, J.S.; Priddy, M.W.; McDowell, D.L.; Kalidindi, S.R. On capturing the grain-scale elastic and plastic anisotropy of alpha-Ti with spherical nanoindentation and electron back-scattered diffraction. Acta Mater. 2016, 117, 23-34. [CrossRef]

59. Weaver, J.S.; Kalidindi, S.R. Mechanical characterization of Ti-6Al-4V titanium alloy at multiple length scales using spherical indentation stress-strain measurements. Mater. Des. 2016, 111, 463-472. [CrossRef]

60. Pathak, S.; Kalidindi, S.R.; Mara, N.A. Investigations of orientation and length scale effects on micromechanical responses in polycrystalline zirconium using spherical nanoindentation. Scr. Mater. 2016, 113, 241-245. [CrossRef]

61. Vachhani, S.J.; Kalidindi, S.R. Grain-scale measurement of slip resistances in aluminum polycrystals using spherical nanoindentation. Acta Mater. 2015, 90, 27-36. [CrossRef]

62. Kalidindi, S.R.; Pathak, S. Determination of the effective zero-point and the extraction of spherical nanoindentation stress-strain curves. Acta Mater. 2008, 56, 3523-3532. [CrossRef]

63. Pathak, S.; Shaffer, J.; Kalidindi, S.R. Determination of an effective zero-point and extraction of indentation stress-strain curves without the continuous stiffness measurement signal. Scr. Mater. 2009, 60, 439-442. [CrossRef]

64. Hertz, H. Miscellaneous Papers; MacMillan and Co. Ltd.: New York, NY, USA, 1896. 
65. Fischer-Cripps, A.C. Critical review of analysis and interpretation of nanoindentation test data. Surf. Coat. Technol. 2006, 200, 4153-4165. [CrossRef]

66. Chudoba, T.; Griepentrog, M.; Dück, A.; Schneider, D.; Richter, F. Young's modulus measurements on ultra-thin coatings. J. Mater. Res. 2004, 19, 301-314. [CrossRef]

67. Chudoba, T.; Schwarzer, N.; Richter, F. Determination of elastic properties of thin films by indentation measurements with a spherical indenter. Surf. Coat. Technol. 2000, 127, 9-17. [CrossRef]

68. Richter, F.; Herrmann, M.; Molnar, F.; Chudoba, T.; Schwarzer, N.; Keunecke, M.; Bewilogua, K.; Zhang, X.W.; Boyen, H.G.; Ziemann, P. Substrate influence in Young's modulus determination of thin films by indentation methods: Cubic boron nitride as an example. Surf. Coat. Technol. 2006, 201, 3577-3587. [CrossRef]

69. Grau, P.; Berg, G.; Fränzel, W.; Meinhard, H. Recording hardness testing. Problems of measurement at small indentation depths. Phys. Status Solidi 1994, 146, 537-548. [CrossRef]

70. Ullner, C. Requirement of a robust method for the precise determination of the contact point in the depth sensing hardness test. Measurement 2000, 27, 43-51. [CrossRef]

71. Lim, Y.Y.; Chaudhri, M.M. Indentation of elastic solids with a rigid Vickers pyramidal indenter. Mech. Mater. 2006, 38, 1213-1228. [CrossRef]

72. Fernandez-Zelaia, P.; Nguyen, V.; Zhang, H.; Kumar, A.; Melkote, S.N. The effects of material anisotropy on secondary processing of additively manufactured CoCrMo. Addit. Manuf. 2019, 29, 100764. [CrossRef]

73. Weaver, J.S.; Jones, D.R.; Li, N.; Mara, N.; Fensin, S.; Gray, G.T. Quantifying heterogeneous deformation in grain boundary regions on shock loaded tantalum using spherical and sharp tip nanoindentation. Mater. Sci. Eng. 2018, 737, 373-382. [CrossRef]

74. Leung, J.F.W.; Bedekar, V.; Voothaluru, R.; Neu, R.W. Mechanical Properties of White Etching Areas in Carburized Bearing Steel Using Spherical Nanoindentation. Metall. Mater. Trans. 2019, 50, 4949-4954. [CrossRef]

75. Pathak, S.; Weaver, J.S.; Sun, C.; Wang, Y.; Kalidindi, S.R.; Mara, N.A. Spherical Nanoindentation Stress-Strain Analysis of Ion-Irradiated Tungsten; Minerals. Metals and Materials Series; Springer International Publishing: New York, NY, USA, 2019; pp. 617-635.

76. Fernandez-Zelaia, P.; Joseph, V.R.; Kalidindi, S.R.; Melkote, S.N. Estimating mechanical properties from spherical indentation using Bayesian approaches. Mater. Des. 2018, 147, 92-105. [CrossRef]

77. Weaver, J.S.; Sun, C.; Wang, Y.; Kalidindi, S.R.; Doerner, R.P.; Mara, N.A.; Pathak, S. Quantifying the mechanical effects of $\mathrm{He}, \mathrm{W}$ and $\mathrm{He}+\mathrm{W}$ ion irradiation on tungsten with spherical nanoindentation. J. Mater. Sci. 2018, 53, 5296-5316. [CrossRef]

78. Iskakov, A.; Yabansu, Y.C.; Rajagopalan, S.; Kapustina, A.; Kalidindi, S.R. Application of spherical indentation and the materials knowledge system framework to establishing microstructure-yield strength linkages from carbon steel scoops excised from high-temperature exposed components. Acta Mater. 2018, 144, 758-767. [CrossRef]

79. Pathak, S.; Kalidindi, S.R.; Weaver, J.S.; Wang, Y.; Doerner, R.P.; Mara, N.A. Probing nanoscale damage gradients in ion-irradiated metals using spherical nanoindentation. Sci. Rep. 2017, 7, 11918. [CrossRef] [PubMed]

80. Khosravani, A.; Cecen, A.; Kalidindi, S.R. Development of high throughput assays for establishing process-structure-property linkages in multiphase polycrystalline metals: Application to dual-phase steels. Acta Mater. 2017, 123, 55-69. [CrossRef]

81. Zhang, Q.; Mochalin, V.N.; Neitzel, I.; Knoke, I.Y.; Han, J.; Klug, C.A.; Zhou, J.G.; Lelkes, P.I.; Gogotsi, Y. Fluorescent PLLA-nanodiamond composites for bone tissue engineering. Biomaterials 2011, 32, 87-94. [CrossRef] [PubMed]

82. Weaver, J.S.; Livescu, V.; Mara, N.A. A comparison of adiabatic shear bands in wrought and additively manufactured $316 \mathrm{~L}$ stainless steel using nanoindentation and electron backscatter diffraction. J. Mater. Sci. 2020, 55, 1738-1752. [CrossRef]

83. Kim, H.N.; Mandal, S.; Basu, B.; Kalidindi, S.R. Probing Local Mechanical Properties in Polymer-Ceramic Hybrid Acetabular Sockets Using Spherical Indentation Stress-Strain Protocols. Integr. Mater. Manuf. Innov. 2019, 8, 257-272. [CrossRef]

84. Pathak, S.; Kalidindi, S.R.; Klemenz, C.; Orlovskaya, N. Analyzing indentation stress-strain response of LaGaO3 single crystals using spherical indenters. J. Eur. Ceram. Soc. 2008, 28, 2213-2220. [CrossRef] 
85. Kalidindi, S.R.; Vachhani, S.J. Mechanical characterization of grain boundaries using nanoindentation. Curr. Opin. Solid State Mater. Sci. 2014, 18, 196-204. [CrossRef]

86. Chang, C.; Verdi, D.; Garrido, M.A.; Ruiz-Hervias, J. Micro-scale mechanical characterization of Inconel cermet coatings deposited by laser cladding. Boletín Sociedad Española Cerámica Vidrio 2016, 55, 136-142. [CrossRef]

87. Weaver, J.; Aydogan, E.; Mara, N.A.; Maloy, S.A. Nanoindentation of Electropolished FeCrAl Alloy Welds; Los Alamos National Lab. (LANL): Los Alamos, NM, USA, 2017.

88. Mohanty, D.P.; Wang, H.; Okuniewski, M.; Tomar, V. A nanomechanical Raman spectroscopy based assessment of stress distribution in irradiated and corroded SiC. J. Nucl. Mater. 2017, 497, 128-138. [CrossRef]

89. Zhang, Q.; Li, X.; Yang, Q.J.A.A. Extracting the isotropic uniaxial stress-strain relationship of hyperelastic soft materials based on new nonlinear indentation strain and stress measure. AIP Adv. 2018, 8, 115013. [CrossRef]

90. Fernandez-Zelaia, P.; Melkote, S.N. Validation of Material Models for Machining Simulation Using Mechanical Properties of the Deformed Chip. Procedia CIRP 2017, 58, 535-538. [CrossRef]

91. Weaver, J.; Nunez, U.C.; Krumwiede, D.; Saleh, T.A.; Hosemann, P.; Nelson, A.T.; Maloy, S.A.; Mara, N.A. Spherical Nanoindentation Stress-Strain Measurements of BOR-60 14YWT-NFA1 Irradiated Tubes; Los Alamos National Lab. (LANL): Los Alamos, NM, USA, 2017.

92. Rossi, A. Mechanical Response of Polymer Matrix Composites Using Indentation Stress-Strain Protocols. Level of Thesis, Georgia Institute of Technology, Atlanta, Georgia, 2018.

93. Khosravani, A. High Throughput Prototyping and Multiscale Indentation Characterization of Metallic Alloys. Level of Thesis, Georgia Institute of Technology, Atlanta, Georgia, 2019.

94. Vachhani, S.J.; Trujillo, C.; Mara, N.; Livescu, V.; Bronkhorst, C.; Gray, G.T.; Cerreta, E. Local Mechanical Property Evolution During High Strain-Rate Deformation of Tantalum. J. Dyn. Behav. Mater. 2016, 2, 511-520. [CrossRef]

95. Weaver, J.S.; Khosravani, A.; Castillo, A.; Kalidindi, S.R. High Throughput Exploration of Process-Property Linkages in Al-6061 using Instrumented Spherical Microindentation and Microstructurally Graded Samples. Integr. Mater. Manuf. Innov. 2016, 5, 192-211. [CrossRef]

96. Donohue, B.R.; Ambrus, A.; Kalidindi, S.R. Critical evaluation of the indentation data analyses methods for the extraction of isotropic uniaxial mechanical properties using finite element models. Acta Mater. 2012, 60, 3943-3952. [CrossRef]

97. Patel, D.K.; Kalidindi, S.R. Correlation of spherical nanoindentation stress-strain curves to simple compression stress-strain curves for elastic-plastic isotropic materials using finite element models. Acta Mater. 2016, 112, 295-302. [CrossRef]

98. Patel, D.K.; Al-Harbi, H.F.; Kalidindi, S.R. Extracting single-crystal elastic constants from polycrystalline samples using spherical nanoindentation and orientation measurements. Acta Mater. 2014, 79, 108-116. [CrossRef]

99. Patel, D.K.; Kalidindi, S.R. Estimating the slip resistance from spherical nanoindentation and orientation measurements in polycrystalline samples of cubic metals. Int. J. Plast. 2017, 92, 19-30. [CrossRef]

100. Ohmura, T.; Tsuzaki, K.; Matsuoka, S. Nanohardness measurement of high-purity Fe-C martensite. Scr. Mater. 2001, 45, 889-894. [CrossRef]

101. Hutchinson, B.; Hagström, J.; Karlsson, O.; Lindell, D.; Tornberg, M.; Lindberg, F.; Thuvander, M. Microstructures and hardness of as-quenched martensites (0.1-0.5\% C). Acta Mater. 2011, 59, 5845-5858. [CrossRef]

102. Molina, R.C.; Pla, M.; Rossi, R.H.; Páramo, J.A.B. Analysis of the decrease of the apparent young's modulus of advanced high strength steels and its effect in bending simulations. In Proceedings of the IDDRG 2009 International Conference, Golden, CO, USA, 1-3 June 2009; pp. 109-117.

103. Chen, Z.; Gandhi, U.; Lee, J.; Wagoner, R.H. Variation and consistency of Young's modulus in steel. J. Mater. Process. Technol. 2016, 227, 227-243. [CrossRef]

104. Rana, R.; Liu, C.; Ray, R.K. Low-density low-carbon Fe-Al ferritic steels. Scr. Mater. 2013, 68, $354-359$. [CrossRef]

105. Furukawa, T.; Morikawa, H.; Endo, M.; Takechi, H.; Koyama, K.; Akisue, O.; Yamada, T. Process Factors for Cold-rolled Dual-phase Sheet Steels. Trans. Iron Steel Inst. Jpn. 1981, 21, 812-819. [CrossRef] 
106. Tomita, Y. Effect of morphology of second-phase martensite on tensile properties of Fe-0.1C dual phase steels. J. Mater. Sci. 1990, 25, 5179-5184.

107. Byun, T.S.; Kim, I.S. Tensile properties and inhomogeneous deformation of ferrite-martensite dual-phase steels. J. Mater. Sci. 1993, 28, 2923-2932. [CrossRef]

108. Chang, C. Correlation between the Microstructure of Dual Phase Steel and Industrial Tube Bending Performance. Master's Thesis, University of Windsor, Windsor, ON, Canada, 2010.

109. Sarwar, M.; Priestner, R. Influence of ferrite-martensite microstructural morphology on tensile properties of dual-phase steel. J. Mater. Sci. 1996, 31, 2091-2095. [CrossRef]

110. Tavares, S.; Pedroza, P.; Teodosio, J.; Gurova, T.J.S.M. Mechanical properties of a quenched and tempered dual phase steel. Scr. Mater. 1999, 40, 887-892. [CrossRef]

111. Bag, A.; Ray, K.; Dwarakadasa, E.J. Influence of martensite content and morphology on tensile and impact properties of high-martensite dual-phase steels. Metall. Mater. Trans. 1999, 30, 1193-1202. [CrossRef]

112. Hayat, F.; Uzun, H. Effect of Heat Treatment on Microstructure, Mechanical Properties and Fracture Behaviour of Ship and Dual Phase Steels. J. Iron Steel Res. Int. 2011, 18, 65-72. [CrossRef]

113. Kocatepe, K.; Cerah, M.; Erdogan, M. Effect of martensite volume fraction and its morphology on the tensile properties of ferritic ductile iron with dual matrix structures. J. Mater. Process. Technol. 2006, 178, 44-51. [CrossRef]

114. Morsdorf, L.; Tasan, C.C.; Ponge, D.; Raabe, D. 3D structural and atomic-scale analysis of lath martensite: Effect of the transformation sequence. Acta Mater. 2015, 95, 366-377. [CrossRef]

115. Bhadeshia, H.K.D.H.; Keehan, E.; Karlsson, L.; Andrén, H.O. Coalesced bainite. Trans. Indian Inst. Met. 2006, 59, 689-694.

116. Rice, J.R. Inelastic constitutive relations for solids: An internal-variable theory and its application to metal plasticity. J. Mech. Phys. Solids 1971, 19, 433-455. [CrossRef]

117. Pedregosa, F.; Varoquaux, G.; Gramfort, A.; Michel, V.; Thirion, B.; Grisel, O.; Blondel, M.; Prettenhofer, P.; Weiss, R.; Dubourg, V.J.J. Scikit-learn: Machine learning in Python. J. Mach. Learn. Res. 2011, 12, 2825-2830.

118. Bergstr, Y.; Granbom, Y.; Sterkenburg, D. A Dislocation-Based Theory for the Deformation Hardening Behavior of DP Steels: Impact of Martensite Content and Ferrite Grain Size. J. Metall. 2010. [CrossRef]

119. Liedl, U.; Traint, S.; Werner, E.A. An unexpected feature of the stress-strain diagram of dual-phase steel. Comput. Mater. Sci. 2002, 25, 122-128. [CrossRef]

120. Lorenz, D.; Zeckzer, A.; Hilpert, U.; Grau, P.; Johansen, H.; Leipner, H.S. Pop-in effect as homogeneous nucleation of dislocations during nanoindentation. Phys. Rev. 2003, 67, 172101. [CrossRef]

121. Ahn, T.-H.; Oh, C.-S.; Lee, K.; George, E.P.; Han, H.N. Relationship between yield point phenomena and the nanoindentation pop-in behavior of steel. J. Mater. Res. 2012, 27, 39-44. [CrossRef]

122. Pathak, S.; Riesterer, J.L.; Kalidindi, S.R.; Michler, J. Understanding pop-ins in spherical nanoindentation. Appl. Phys. Lett. 2014, 105, 161913. [CrossRef]

123. Wang, M.G.; Ngan, A.H.W. Indentation strain burst phenomenon induced by grain boundaries in niobium. J. Mater. Res. 2004, 19, 2478-2486. [CrossRef]

124. Morris, J.R.; Bei, H.; Pharr, G.M.; George, E.P. Size effects and stochastic behavior of nanoindentation pop in. Phys. Rev. Lett. 2011, 106, 165502. [CrossRef] [PubMed]

125. Phani, P.S.; Johanns, K.E.; George, E.P.; Pharr, G.M. A stochastic model for the size dependence of spherical indentation pop-in. J. Mater. Res. 2013, 28, 2728-2739. [CrossRef]

126. Ohmura, T.; Hara, T.; Tsuzaki, K. Evaluation of temper softening behavior of Fe-C binary martensitic steels by nanoindentation. Scr. Mater. 2003, 49, 1157-1162. [CrossRef]

127. Speich, G.R.; Leslie, W.C. Tempering of steel. Metall. Trans. 1972, 3, 1043-1054. [CrossRef]

128. Caron, R.N.; Krauss, G. The tempering of Fe-C lath martensite. Metall. Trans. 1972, 3, 2381-2389. [CrossRef]

129. Tkalcec, I.; Azcoitia, C.; Crevoiserat, S.; Mari, D. Tempering effects on a martensitic high carbon steel. Mater. Sci. Eng. 2004, 387, 352-356. [CrossRef]

130. Ohmura, T.; Tsuzaki, K.; Matsuoka, S. Evaluation of the matrix strength of Fe- $0.4 \mathrm{wt} \% \mathrm{C}$ tempered martensite using nanoindentation techniques. Philos. Mag. 2002, 82, 1903-1910.

131. Waseda, O.; Veiga, R.G.A.; Morthomas, J.; Chantrenne, P.; Becquart, C.S.; Ribeiro, F.; Jelea, A.; Goldenstein, H.; Perez, M. Formation of carbon Cottrell atmospheres and their effect on the stress field around an edge dislocation. Scr. Mater. 2017, 129, 16-19. [CrossRef] 
132. Pereloma, E.V.; Miller, M.K.; Timokhina, I.B. On the decomposition of martensite during bake hardening of thermomechanically processed transformation-induced plasticity steels. Metall. Mater. Trans. 2008, 39, 3210-3216. [CrossRef]

133. Waterschoot, T.; de Cooman, B.C.; De, A.K.; Vandeputte, S. Static strain aging phenomena in cold-rolled dual-phase steels. Metall. Mater. Trans. 2003, 34, 781-791. [CrossRef]

134. Suresh, S.; Nieh, T.G.; Choi, B.W. Nano-indentation of copper thin films on silicon substrates. Scr. Mater. 1999, 41, 951-957. [CrossRef]

135. Michalske, T.A.; Houston, J.E. Dislocation nucleation at nano-scale mechanical contacts. Acta Mater. 1998, 46, 391-396. [CrossRef]

136. Pathak, S.; Stojakovic, D.; Doherty, R.; Kalidindi, S.R. Importance of surface preparation on the nano-indentation stress-strain curves measured in metals. J. Mater. Res. 2009, 24, 1142-1155. [CrossRef]

(C) 2019 by the authors. Licensee MDPI, Basel, Switzerland. This article is an open access article distributed under the terms and conditions of the Creative Commons Attribution (CC BY) license (http://creativecommons.org/licenses/by/4.0/). 